\title{
Do institutions matter for economic fluctuations? Weak property rights in a business cycle model for Mexico
}

\author{
by \\ Konstantinos Angelopoulos a, George Economides ${ }^{b, *}$ and Vangelis Vassilatos ${ }^{c}$ \\ a Department of Economics, University of Glasgow, Adam Smith Building, Glasgow G12 8RT, United Kingdom. \\ Tel.: +44 (0) 141330 5273; Fax: +44 (0) 141330 4940. Email:k.angelopoulos@lbss.gla.ac.uk \\ ${ }^{b}$ Department of International and European Economic Studies, Athens University of Economics and Business, 76 \\ Patission street, Athens 104 34, Greece. Tel.: +30 210 8203729; Fax: +30 210 8214122. Email: gecon@aueb.gr \\ c Department of Economics, Athens University of Economics and Business, 76 Patission street, Athens 104 34, \\ Greece. Tel.: +30 210 8203716; Fax: +30 210 8203716. Email: vvassila@aueb.gr
}

December 31, 2008

\begin{abstract}
This paper shows that introducing weak property rights in the standard real business cycle (RBC) model can help to explain economic fluctuations. This is motivated by the empirical observation that changes in institutions in emerging markets are related to the evolution of the main macroeconomic variables. In particular, in Mexico, the movements in productivity in the data are associated with changes in institutions, so that we can explain productivity shocks to a large extent as shocks to the quality of institutions. We find that the model with shocks to the degree of protection of property rights only - without technology shocks - can match the second moments in the data for Mexico well. In particular, the fit is better than that of the standard neoclassical model with full protection of property rights regarding the auto-correlations and cross-correlations in the data, especially those related to labor. Viewing productivity shocks as shocks to institutions is also consistent with the stylized fact of falling productivity and non-decreasing labor hours in Mexico over 1980-1994, which is a feature that the neoclassical model cannot match.
\end{abstract}

Keywords: Economic fluctuations, institutions, property rights.

JEL classification: E32, E62, D7.

Acknowledgements: We are grateful to two anonymous referees for comments and suggestions. We also thank Jim Malley, Evi Pappa, Apostolis Philippopoulos, Sergio Rebelo, David Vasquez-Guzman, Uli Woitek, seminar participants at the University of Cambridge and conference participants at the 2008 ASSET conference organized by the European University Institute and the Dynamics, Optimal Growth and Population Change workshop organized by the University of Milan for comments and discussions. Any errors are ours.

\footnotetext{
${ }^{*}$ Corresponding author.
} 
"If (technology shocks) are large and important, why can't we read about them in the Wall Street Journal?" (King and Rebelo, 1999, p. 962)

\section{Introduction}

In the real business cycle $(\mathrm{RBC})$ model, technology shocks are central to the interpretation of cycles (see e.g. King and Rebelo, 1999 and Rebelo, 2005, for reviews of this literature). However, with the exception of some big oil shocks, it is hard to find macro events such as the ones suggested by the Solow residual. Adopting a broader definition of technology shocks (so as to include disturbances like policy reforms, financial and political crises, weather conditions, wars, etc) could help in this direction. Such disturbances, however, work through different economic channels. It is hence arbitrary to put all of them in the same basket and assume that they all work in the same way, as implied by treating them as technology shocks in the baseline RBC model.

The literature has therefore searched for extra shocks that can potentially reduce the dependence on unobservable technology shocks, as well as for mechanisms to amplify and propagate these shocks (see e.g. Rebelo, 2005, pp. 224227). Simply adding shocks does not necessarily improve the fit of a model; what is also important is the channel through which these shocks affect the macro-economy (see e.g. Cooley and Hansen, 1995).

In the present paper, we study a new shock that works via a new channel and is potentially relevant for a number of countries, especially emerging markets. In particular, we emphasize the role of institutions for the macro-economy. This is because it is widely recognized that the incentives to work, produce, invest, innovate, etc, depend crucially on the quality of institutions in general, and the degree of protection of property rights in particular. The less secure are the property rights, the weaker these incentives, and this is bad for the macro-economy.

Although the importance of institutions for economic outcomes has been emphasized by many researchers at both a theoretical ${ }^{1}$ and empirical ${ }^{2}$ level, the literature has not paid as much attention on whether accounting for institutional

\footnotetext{
${ }^{1}$ See e.g. North (1990) and Parente and Prescott (2000) for the importance of institutions. For a survey on institutions, property rights and economic outcomes, see e.g. Drazen (2000) and Mueller (2003). Prescott (1998) suggests that changes in institutions are behind the differences in total factor productivity.

${ }^{2}$ See e.g. Knack and Keefer (1995), Mauro (1995), Hall and Jones (1999), Rodrik (1999), Acemoglu et al. $(2001,2002)$ and Acemoglu et al. (2003).
} 
characteristics, like the degree of property rights, can contribute to explaining the cyclical properties of the data within a dynamic stochastic general equilibrium framework. ${ }^{3}$

We focus on the Mexican economy, motivated by Bergoeing et al. (2002a, 2002b), who have suggested that in Chile and Mexico institutional changes (such as privatization, regulation of the banking system and bankruptcy laws) can help to explain the total factor productivity movements, which in turn shape economic fluctuations. Indeed, we find that in Mexico the movements in productivity are associated with the evolution of institutions. Hence, here we model unobserved technology shocks as institutional changes, and find that shocks to institutions drive economic fluctuations, by working through productivity as well as through direct effects on resource allocation. Hence, as shocks to property rights are identified, as opposed to unobserved technology shocks, we give a potential explanation to what is hinted at in our opening quotation.

Using data on the evolution of the quality of institutions from the ICRG dataset (this dataset is widely used in the literature on institutions; see e.g. the papers in footnote 2 and Appendix B for details), we construct a measure of the quality of institutions that protect property rights. We find that changes in this measure are related to the evolution of the main macroeconomic variables, especially in emerging markets where the property rights measure has a higher standard deviation. We then incorporate weak property rights into an otherwise standard RBC model, by assuming that individuals can use a share of their non-leisure (or work) time to extract from other individuals' output to increase their own personal wealth. This hurts the macro-economy because the possibility of weak property rights pushes rational individuals away from productive activities and thus leads to a misallocation of talent and resources (see also e.g. Murphy et al., 1991).

In our model, a shock to the degree of property rights affects the efficiency with which factor inputs are used. As a result, the effects of a property rights' shock resemble to those of a technology shock. This is a useful characteristic, because economic fluctuations are related to total factor productivity (TFP). However, a negative shock to property rights, by creating incentives for extraction, has additional direct effects on factor inputs, which, in the case of the labor input, result

\footnotetext{
${ }^{3}$ For instance, Acemoglu et al. (2003) have shown that weaker institutions are related to higher volatility in a world sample. See also Bergoeing et al. (2002a, 2002b) and the next section for more details.
} 
in increases in labor hours three periods after a negative property rights shock. Given that in this framework negative shocks to property rights show up as negative TFP shocks, this model is then consistent with falling productivity and non-decreasing labor supply in the data in the medium run. Hence, it is consistent with the stylized fact of falling productivity and non-decreasing labor hours in Mexico over 1980-1994, which is a feature that the basic RBC model driven by technology shocks cannot match.

We then calibrate this model to Mexican annual data over the period 19802005. We find that the model with weak property rights performs generally better than the model with full protection of property rights (which is the baseline RBC model) in matching the auto-correlations and cross correlations in the data, especially the auto-correlations and cross correlations related to labor hours. Hence, it is more likely to be seen as the data generating process compared to a model with full protection of property rights.

The model with weak property rights also reproduces the empirical regularity observed in the data regarding the correlation between the quality of institutions and the main economic variables. Moreover, sensitivity analysis in the long-run and impulse response functions show that weak property rights have, indeed, a pervasive effect on the functioning of the economy, by reducing income, investment and consumption and eventually welfare.

Finally, when we use the measure of property rights constructed from the ICRG dataset to obtain a proxy for the driving process in the model with weak property rights, we find that the model with such a shock only (i.e., without an additional technology shock) can generate series that follow the actual data until the early 90s and then again after 2000. When compared to the basic RBC model with full protection of property rights that is driven by TFP shocks (as measured by the actual Solow residual from the data) the model that has only shocks to property rights still does a better job in matching the actual data for the period 1984-1994. The model with weak property rights that is driven by both TFP and property rights shocks gives a better fit for the whole period.

Obviously, shocks to the quality of institutions are not the only shocks that matter for economic fluctuations. This is evident in the case of Mexico as the model, when driven by property right shocks only, cannot fit the data in the mid and late nineties as well as a model with both TFP and property rights shocks. In the period during and after the debt crisis of 1995, movements in current accounts, capital flows 
and exchange rates are also a very important part of the story (see e.g. Chari et al., 2005, Kehoe and Ruhl, 2007, and Meza and Quintin, 2007), that we do not model. Here, we consider a simple extension to the benchmark closed economy neoclassical model and we find that this simple extension contributes to accounting for economic fluctuations in Mexico and can be useful both in characterizing the nature of (some) shocks and in providing a potential explanation for (some) stylized facts.

The rest of the paper is organized as follows. Section 2 motivates the paper by briefly discussing the literature on institutions and presenting some empirical evidence. Section 3 presents and solves the theoretical model and discusses the role of weak property rights. Section 4 calibrates the model. Section 5 discusses the model's predictions. Section 6 compares the model with weak property rights to the model with full protection of property rights, by evaluating their ability to reproduce some key second moments in the actual data. Section 7 uses a proxy for the protection of property rights, obtained using data from the ICRG dataset, to compare the predictions of the model with weak property rights to those of the benchmark model that is driven by the actual Solow residual. Finally, section 8 closes the paper.

\section{Empirical motivation}

There is a rich literature on the importance of the quality of institutions for macro outcomes, using data averages from cross sections of countries. For instance, weak institutions are shown to be a significant impediment to private investment (see e.g. Knack and Keefer, 1995, Mauro, 1995, and Hall and Jones, 1999) and to be negatively related to productivity (Hall and Jones, 1999), income per capita (Acemoglu et al. 2001) and growth and development (Knack and Keefer, 1995, Rodrik, 1999, and Acemoglu et al. 2002). In addition, Acemoglu et al. (2003) have shown that weaker institutions are related to higher volatility in a cross section of countries. Evidence across countries therefore suggests that the institutional characteristics of an economy are significantly related to macroeconomic data averages.

However, certain features of the institutional environment of a country change over time and one would expect such changes to have an effect on the observed macroeconomic data, since the institutional environment shapes economic choices. We would then expect shocks to the quality of institutions to affect economic fluctuations, especially in countries where the quality of institutions is an important issue. For example, Bergoeing et al. (2002a, 2002b) suggest that institutional changes, 
in the form of privatization, the regulation of the banking system and bankruptcy laws are essentially the driving force of the total factor productivity (TFP) movements in Chile and Mexico, which in turn shape economic fluctuations in these two countries.

To examine whether the data indicate that there is indeed such a relationship between the institutional characteristics of the economy and the evolution of some key economic variables, we use the ICRG dataset, which is widely used in the related literature (see e.g. the empirical papers referred to above), to obtain a proxy for the quality of institutions, that has a sufficient time series dimension. To obtain an empirical measure of the quality of institutions that protect property rights, we use Political Risk Components of the ICRG index that are related to institutional quality and construct a variable where higher scores imply better outcomes. We denote this variable as $P R$ (more details on the $P R$ variable and the other data used here are discussed in Appendix B). We first look at the standard deviation of $P R$, as a measure of the volatility of the quality of institutions. This is calculated for a group of developed economies and for a group of emerging markets. The results, reported in the first column in Table 1, show that, as expected, institutions are more volatile in the emerging markets. This implies that shocks to the quality of institutions are larger in these economies.

We then look at the correlations between the de-trended (using the HodrickPrescott filter) $P R$ and de-trended per capita income, consumption and investment, over 1984-2005, which is the time period that the ICRG data is available (we do not include data on hours worked, as such data are not available for many countries for most of the time period). These correlations are reported in columns (2)-(4) of Table 1 below. These statistics are calculated for both developed and emerging economies. We would expect the correlations to be positive in general, as an increase in $P R$ implies an improvement in institutions, and larger for the countries where the quality of institutions is an important issue, i.e. where the volatility of $P R$ is larger.

\section{[Table 1 here]}

The correlations are indeed positive for the emerging markets and on average they are quite high. It is interesting to note that the correlations are positive for Chile and Mexico, in accordance with the arguments suggested by Bergoeing et al. (2002a, 
$2002 b)$ for these two countries. On the contrary, the correlations are on average low or even have a negative sign for the developed countries.

Overall, the correlations in Table 1 suggest that changes in institutions matter for emerging markets, at least over the last 25 year period. Most of the developed countries seem to have established a level of institutional framework that promotes but does not interfere with economic activity, in the sense that changes in this framework are not fundamental and hence do not affect economic variables as much as in emerging markets. Emerging markets are in the process of building up their institutional framework, so that changes are fundamental and shape economic choices. This interpretation is consistent with the evidence from the first column in Table 1, which suggests that shocks to institutions are larger for emerging markets. To sum up, although for some developed countries the quality of institutions does seem to be related to the macro-economy, the pattern is clearly stronger for emerging markets. We focus therefore on emerging markets.

Motivated by the above, we incorporate, in this paper, an institutional characteristic, weak property rights, in a standard real business cycle model for an emerging market (Mexico) that is characterized by the above empirical regularity, namely the positive correlation of the quality of institutions with both the level and the cyclical component of the main macro variables. ${ }^{4}$ The aim is to construct a model that matches this empirical regularity and investigate whether this simple extension to the standard RBC model helps to predict economic fluctuations and reduce the model's dependence on technology shocks. We model changes in the degree of protection of property rights due to exogenous factors, for instance legal or political developments. Such changes directly affect the efficiency with which factor inputs are used and are thus in the spirit of Bergoeing et al. (2002a, 2002b). In general, examples of positive changes in property rights can include a new constitution or a significant improvement of the legal system, while, on the other hand, negative shocks may include political and social instability or even a civil war.

We choose Mexico, because it is a country that looks particularly suitable for our study. The institutional reforms suggested by Bergoeing et al. (2002a, 2002b) are obviously related to how well-defined and protected property rights are. For instance, banks were highly regulated and the government set very low deposit rates

\footnotetext{
${ }^{4}$ Modelling the effects of institutions as property rights problems is probably not representative of more developed economies, where property rights are, more or less, secure. In these countries, if there is an effect of institutions in the macro-economy, this probably works via other channels.
} 
to give low-interest loans to preferred industries: "the banking system in Mexico was used by the government as a way to channel funds to preferred borrowers at low interest rates" (Bergoeing et al., 2002b, p. 182). This implies a redistribution from investors to borrowers; essentially, such a policy "taxes" investors and creates a pie of funds available for borrowers. In turn, borrowers will find it optimal to expend resources to fight for a share of these funds.

Moreover, in Mexico, the bankruptcy law in place until 2000 was "obsolete and unwieldy" ((Bergoeing et al., 2002b, p. 183). Bankruptcy procedures create further opportunities for redistribution when property rights are not clearly defined. When bankruptcy laws do not clearly define the rights of each creditor, they have the incentive to engage in a struggle to secure as much of the value of the bankrupt firm as possible. In addition, in Mexico the government nationalized the banking system in the beginning of the $80 \mathrm{~s}$ and effectively appropriated the bank's holdings of private companies, in an effort to prevent bankrupt firms from collapsing. The institutional setup was hence such that fiscal policy may have been used to redistribute income from taxpayers to those who had a vested interest in the bankrupt firm (e.g. shareholders, employees, etc). The value of the nationalized firm then is sustained by taxing the productive economy. Later re-privatization, in an inadequate institutional framework, can result in a transformation of these social resources (i.e. the value of the firm), to a big contestable prize for rent seekers. ${ }^{5}$

Mexico has also experienced political shocks, as for instance those related to the debt crisis of 1994-1995. This was due to the inability, and maybe bad luck, of the Mexican government to make a smooth transition from the administration of President Salinas de Gortari (1986-1994) to the administration of President Zedillo (1994-2000). This started as a political crisis that affected the quality of institutions and soon transformed into an economic crisis when there was a sudden stop in capital inflows in the country (see e.g. Kehoe and Ruhl, 2007 and Meza and Quintin, 2007). ${ }^{6}$

\footnotetext{
${ }^{5}$ Obviously, institutions associated with fiscal policy, poor regulation of the banking system and insufficient legal framework are very good candidates for shocks in more developed economies as well. However, since the channels via which they work in developed economies are more complicated, they require different modeling to weak protection of the national output, as we do in this paper.

${ }^{6}$ In January 1994, the EZLN (Zapatista Army for National Freedom -Ejercito Zapatista de Liberacion Nacional) begun hostilities with the Mexican Army. Three months later, the state party's (PRI) presidential candidate for the coming elections in June, Luis Donaldo Colosio, was assassinated. In September, the PRI's General Secretary was also assassinated. In this adverse environment, the new government administration by Dr. Ernesto Zedillo was unable to make a successful transition from the previous administration. This political crisis was rapidly transformed into an economic crisis, as in the last weeks of 1994 the "sudden stop” begins, when the Banco de Mexico has trouble rolling over the
} 
There is a small literature on using dynamic stochastic general equilibrium (DSGE) models to analyze certain features of the Mexican economy, most notably the effects of "sudden stops" and financial crises in rich open economy setups (see e.g. Kehoe and Ruhl, 2007 and Meza and Quintin, 2007) by focusing on the debt crisis of 1995. Aguiar and Gopinath (2007) have constructed a DSGE model that includes shocks to the trend growth rate in order to explain some features of the pattern of data in emerging markets, especially the high consumption volatility, countercyclical current accounts and sudden stops in capital inflows (see also Neumeyer and Perri, 2005, for stylized facts in emerging markets). Here, instead, we choose to work with the benchmark closed economy RBC model to demonstrate that shocks to institutions drive economic fluctuations, by working through productivity as well as through direct effects on resource allocation.

\section{Theoretical model}

We start by discussing the model. We incorporate weak property rights into a standard RBC model. The key ingredients of the model are as in Economides et al. (2007). There is a large number of identical households and (for simplicity) an equal number of identical firms. We assume that households can extract from firms' output in an attempt to increase their own personal wealth. ${ }^{7}$ Specifically, firms can appropriate only a fraction, $0<\left(1-\theta_{t}\right) \leq 1$, of their output produced, because the rest, $0 \leq \theta_{t}<1$, can be taken away by households. Thus, $0 \leq\left(1-\theta_{t}\right)<1$ is the degree of protection of property rights. This is consistent with the examples of institutional weaknesses given for Mexico in the previous section, where a share of the national output produced is essentially extracted by the participants in the economy, as property rights over that output are not clearly defined. Here extraction takes the form of rent-seeking competition. Following most of the literature, expropriation comes at a private cost: it requires effort (non-leisure) time. Thus, in addition to consumption, leisure, and saving, each household also chooses optimally how to allocate its non-leisure time between productive work and unproductive (extraction)

government's debt. The combination of bad policies and the inadequate institutional environment (e.g. privatization of banks without the necessary regulation) over the previous years had left the economy vulnerable to institutional shocks (see e.g. Lustig, 2001).

${ }^{7}$ There are many ways of modeling expropriation. For instance, firms may attempt to expropriate each other's capital or output, or households may attempt to expropriate each other's assets, or a combination of both. The specific way of modeling "who takes away from whom" is not important in this class of general equilibrium models because households are also firm-owners. 
activities. ${ }^{8}$ Firms produce a homogenous product by using capital and labour. Assuming away property rights issues, the model is similar to the baseline RBC model.

In what follows, we solve the problems of individual households and firms and then the associated decentralized competitive equilibrium. Individuals are rational. Time is discrete and infinite.

\subsection{Households}

Each period $t$ there are $N_{t}$ identical households indexed by the superscript $h$, where $h=1,2, \ldots, N_{t}$. The population size, $N_{t}$, evolves at a constant rate $\gamma_{n} \geq 1$ so that $N_{t+1}=\gamma_{n} N_{t}$, where $N_{0}>0$ is given.

The expected lifetime utility of household $h$ is:

$E_{0} \sum_{t=0}^{\infty} \beta^{* t} u\left(C_{t}^{h}, L_{t}^{h}\right)$

where $E_{0}$ denotes rational expectations conditional on the information set available at time zero, $0<\beta^{*}<1$ is a time discount factor, $C_{t}^{h}$ is $h^{\prime}$ s consumption at time $t$, and $L_{t}^{h}$ is $h^{\prime}$ s leisure time at $t$.

Concerning the instantaneous utility function, we assume the form:

$u\left(C_{t}^{h}, L_{t}^{h}\right)=\frac{\left(\left(C_{t}^{h}\right)^{\mu}\left(L_{t}^{h}\right)^{1-\mu}\right)^{1-\sigma}-1}{1-\sigma}$

where $0<\mu<1$ is the weight given to consumption relative to leisure, and $1 / \sigma>0$ is the intertemporal elasticity of substitution.

Each household $h$ saves in the form of investment in capital, $I_{t}^{h}$. It receives interest income from capital, $r_{t} K_{t}^{h}$, where $r_{t}$ is the gross return to inherited capital, $K_{t}^{h}$. In addition, each household receives a share of profits, $\Pi_{t}^{h}$. The household has one unit of time in each period and divides it between leisure, $L_{t}^{h}$, and work time,

\footnotetext{
${ }^{8}$ This goes back to Baumol (1990), Murphy et al. (1991) and many others, where individuals decide how to allocate their activities between socially productive and socially unproductive ones.
} 
$H_{t}^{h}$. Thus, $L_{t}^{h}+H_{t}^{h}=1$ in each period. Further, while at work, it divides its work time $H_{t}^{h}$, between productive work, $\eta_{t}^{h} H_{t}^{h}$, and extraction activities, $\left(1-\eta_{t}^{h}\right) H_{t}^{h}$. Essentially, the assumption we make is that the household chooses its labor effort $\eta_{t}^{h}$ in addition to its labor hours $H_{t}^{h}$, so that only $\eta_{t}^{h} H_{t}^{h}$ of the overall labor hours is the effective labor input. 9 The rest of the effort time $\left(1-\eta_{t}^{h}\right) H_{t}^{h}$, while at work, is used for rent seeking, or extraction activities. This captures the idea that activities that are aimed at the redistribution (or appropriation) of a share of national income when property rights are not clearly defined, like efforts for privileged transfers and subsidies, lobbying, bribing, union membership, building up networks of connections, etc, are at the cost of work time.

The household's budget constraint is:

$$
C_{t}^{h}+I_{t}^{h}=r_{t} K_{t}^{h}+w_{t} Z_{t} \eta_{t}^{h} H_{t}^{h}+\Pi_{t}^{h}+\frac{\left(1-\eta_{t}^{h}\right) H_{t}^{h}}{\sum_{h=1}^{N_{t}}\left(1-\eta_{t}^{h}\right) H_{t}^{h}} \theta_{t} Y_{t}
$$

where $w_{t}$ is the wage rate, $Z_{t}$ is labour-augmenting technology, common to all households, that evolves at a constant rate $\gamma_{z} \geq 1$ so that $Z_{t+1}=\gamma_{z} Z_{t}$ where $Z_{0}>0$ is given, $Y_{t}$ denotes aggregate output produced (specified below) and $0 \leq \theta_{t}<1$ is the economy-wide degree of extraction (whose exogenous motion is specified below). The higher is $\theta_{t}$, the weaker is the degree of protection of property rights.

The idea behind the last term on the right-hand side of (3) is that there is a contestable prize available (defined as $\theta_{t} Y_{t}$ ) due to poor institutions or social norms, and in turn each utility-maximizing individual attempts to grab a fraction of that prize where the fraction depends on the extractive effort he puts relative to the extractive efforts put by all individuals. This is a popular extraction technology (see e.g. Mueller, 2003, chapter 15, for a review).

Private holding of capital evolves according to:

$$
K_{t+1}^{h}=(1-\delta) K_{t}^{h}+I_{t}^{h}
$$

\footnotetext{
${ }^{9}$ This way of modeling extraction activities also implies that the production function of the model is similar to the factor hoarding models introduced and analyzed by Burnside et al. (1993) and Burnside and Eichenbaum (1996). This will be discussed in more detail later.
} 
where the parameter $0<\delta<1$ is a depreciation rate, and the initial $K_{0}^{h}$ is given.

Each household $h$ acts competitively by taking prices and economy-wide variables as given. ${ }^{10}$ Thus, each $h$ chooses $\left\{C_{t}^{h}, H_{t}^{h}, \eta_{t}^{h}, K_{t+1}^{h}\right\}_{t=0}^{\infty}$ to maximize (1)-(2) subject to (3)-(4), $L_{t}^{h}+H_{t}^{h}=1, H_{t}^{h}=n_{t}^{h} H_{t}^{h}+\left(1-n_{t}^{h}\right) H_{t}^{h}$ and $K_{0}^{h}$ given. The firstorder conditions include the constraints above and also:

$$
\begin{aligned}
& \frac{\partial u_{t}(.)}{\partial L_{t}^{h}}=\frac{\partial u_{t}(.)}{\partial C_{t}^{h}}\left[w_{t} Z_{t} \eta_{t}^{h}+\frac{\left(1-\eta_{t}^{h}\right)}{\sum_{h=1}^{N_{t}}\left(1-\eta_{t}^{h}\right) H_{t}^{h}} \theta_{t} Y_{t}\right] \\
& w_{t} Z_{t} H_{t}^{h}=\frac{H_{t}^{h}}{\sum_{h=1}^{N_{t}}\left(1-\eta_{t}^{h}\right) H_{t}^{h}} \theta_{t} Y_{t} \\
& \frac{\partial u_{t}(.)}{\partial C_{t}^{h}}=\beta^{*} E_{t}\left[\frac{\partial u_{t+1}(.)}{\partial C_{t+1}^{h}}\left(r_{t+1}+1-\delta\right)\right]
\end{aligned}
$$

Condition (5a) is the optimality condition with respect to effort time, $H_{t}^{h}$, and equates the marginal value of leisure to the return to effort. Condition (5b) is the optimality condition with respect to the fraction of non-leisure time allocated to work vis-à-vis extraction, $\eta_{t}^{h}$. It implies that, in equilibrium, the return to work and the return to extraction should be equal. Condition (5c) is the Euler equation for $K_{t+1}^{h}$. The optimality conditions are completed by the transversality condition for capital, $\lim _{t \rightarrow \infty} \beta^{* t} E_{0} \frac{\partial u_{t}(.)}{\partial C_{t}^{h}} K_{t+1}^{h}=0$.

\subsection{Firms}

There are as many firms as households. Identical firms are indexed by the superscript $f$, where $f=1,2, \ldots, N_{t}$. Each firm produces a homogeneous product,

\footnotetext{
${ }^{10}$ Each individual $h$ is small by taking economy-wide variables $\left(\theta_{t}, Y_{t}\right.$ and $\left.\sum_{h=1}^{N_{t}}\left(1-\eta_{t}^{h}\right) H_{t}^{h}\right)$ as given. We could alternatively assume that each $h$ internalizes the effects of his/her own actions on aggregate outcomes by taking only the actions of other agents $j \neq h$ as given. This is not important regarding the features of a decentralized equilibrium. What is important is that there are (social) external effects.
} 
$Y_{t}^{f}$, by using private capital, $K_{t}^{f}$ and private effective labor, $Q_{t}^{f}$. Each firm can appropriate only a fraction $0<1-\theta_{t} \leq 1$ of its output produced, $Y_{t}^{f}$, because the rest, $\theta_{t} Y_{t}^{f}$, can be taken away by households. The firm produces according to a neoclassical production function:

$Y_{t}^{f}=A_{t}\left(K_{t}^{f}\right)^{\alpha}\left(Q_{t}^{f}\right)^{1-\alpha}$

where $A_{t}>0$ is stochastic total productivity (see below for its law of motion) and $0<\alpha<1$ is a parameter.

Each firm $f$ acts competitively by taking prices and economy-wide variables as given. Thus, each $f$ chooses $K_{t}^{f}$ and $Q_{t}^{f}$ to maximize a series of static profit problems:

$\Pi_{t}^{f}=\left(1-\theta_{t}\right) Y_{t}^{f}-r_{t} K_{t}^{f}-w_{t} Q_{t}^{f}$

where, as said above, $0<\left(1-\theta_{t}\right) \leq 1$ is the degree of protection of property rights.

The first-order conditions are simply:

$$
\begin{aligned}
& \frac{\alpha\left(1-\theta_{t}\right) Y_{t}^{f}}{K_{t}^{f}}=r_{t} \\
& \frac{(1-\alpha)\left(1-\theta_{t}\right) Y_{t}^{f}}{Q_{t}^{f}}=w_{t}
\end{aligned}
$$

so that there are only normal profits, $\Pi_{t}^{f}=0$, per firm.

As can be seen from equation (7), when property rights are not properly defined and fully protected, so that $0<\left(1-\theta_{t}\right)<1$, a share of the output produced is extracted. In turn, equations (8a)-(8b) imply that households cannot capture all the returns to their investment and labor effort. The share that weak property rights allow to be extracted becomes then a contestable prize for which agents compete as 
in (3). This modeling is consistent with the examples of institutional failures discussed in section 2.11

\subsection{Exogenous stochastic processes for $A_{t}$ and $\theta_{t}$}

The exogenous stochastic variables include the aggregate productivity, $A_{t}$, and the degree of violation of property rights, $\theta_{t}$. We assume that $A_{t}$ and $\theta_{t}$ follow univariate stochastic $A R(1)$ processes of the form:

$$
\begin{aligned}
& \ln A_{t+1}=\left(1-\rho_{a}\right) \ln A_{0}+\rho_{a} \ln A_{t}+\varepsilon_{t+1}^{a} \\
& \ln \theta_{t+1}=\left(1-\rho_{\theta}\right) \ln \theta_{0}+\rho_{\theta} \ln \theta_{t}+\varepsilon_{t+1}^{\theta}
\end{aligned}
$$

where $A_{0}$ and $\theta_{0}$ are means of the stochastic processes; $\rho_{a}$ and $\rho_{\theta}$ are first-order autocorrelation coefficients; and $\varepsilon_{t}^{a}, \varepsilon_{t}^{\theta}$ are i.i.d. shocks.

\subsection{Decentralized Competitive Equilibrium (DCE)}

In a Decentralized Competitive Equilibrium (DCE): (i) Each individual household and each individual firm maximize respectively their own utility and profit by taking as given market prices and economy-wide outcomes. (ii) Markets clear via price flexibility. ${ }^{12}$

We solve for a symmetric DCE in which households and firms are alike ex post. Equilibrium quantities are denoted by letters without the superscripts $h$ (which was used to indicate quantities chosen by households) and $f$ (which was used to indicate quantities chosen by firms).

\footnotetext{
${ }^{11}$ Fiscal policy in an inadequate institutional framework, which is also related to the institutional failures discussed in Section 2, is another example consistent with this modeling. For instance, when the government taxes economic activities, it creates a pool of resources, which can be seen as a contestable prize by the economic agents. In other words, when institutions are weak, so that it is not clear who will benefit from public spending, then participants in the economy will compete for privileged transfers and subsidies, tax exemptions, targeted public goods provision, etc. Such privileged transfers that are obtained as a result of corruption and rent seeking activities can be captured by our modeling above.

${ }^{12}$ Thus, in each time period, $\sum_{f=1}^{N_{t}} K_{t}^{f}=\sum_{h=1}^{N_{t}} K_{t}^{h}$ in the capital market, $\sum_{f=1}^{N_{t}} Q_{t}^{f}=Z_{t} \sum_{h=1}^{N_{t}} \eta_{t}^{h} H_{t}^{h}$ in the labor market and $\sum_{f=1}^{N_{t}} \Pi_{t}^{f}=\sum_{h=1}^{N_{t}} \Pi_{t}^{h}$ in the dividend market.
} 
The DCE is given by equations (1)-(9). Looking ahead at the long run where all components of the national income identity should grow at the same constant rate (the so-called balanced growth rate), we transform these components in per capita and efficient unit terms to make them stationary. Thus, for any economy-wide variable $X_{t}$, where $X_{t} \equiv\left(Y_{t}, C_{t}, K_{t}, I_{t}\right)$, we define $x_{t} \equiv \frac{X_{t}}{N_{t} Z_{t}}$. We also define $h_{t} \equiv \frac{H_{t}}{N_{t}}$ to be per capita non-leisure time. Thus, the economy grows in the long run because of labor augmenting technology and population growth. It is straightforward to show that (1)-(9) imply the following stationary DCE:

$$
\begin{aligned}
& \frac{c_{t}}{\left(1-h_{t}\right)}=\frac{\mu}{(1-\mu)}\left(\frac{\left((1-\alpha)\left(1-\theta_{t}\right)+\theta_{t}\right) y_{t}}{h_{t}}\right) \\
& \eta_{t}=\frac{(1-\alpha)\left(1-\theta_{t}\right)}{\theta_{t}+(1-\alpha)\left(1-\theta_{t}\right)} \\
& \frac{\left(c_{t}^{\mu}\left(1-h_{t}\right)^{1-\mu}\right)^{1-\sigma}}{c_{t}}=\beta E_{t}\left[\frac{\left(c_{t+1}{ }^{\mu}\left(1-h_{t+1}\right)^{1-\mu}\right)^{1-\sigma}}{c_{t+1}}\left[\frac{\alpha\left(1-\theta_{t+1}\right) y_{t+1}}{k_{t+1}}+1-\delta\right]\right]
\end{aligned}
$$

$y_{t}=c_{t}+i_{t}$

$y_{t}=A_{t} k_{t}^{\alpha}\left(\eta_{t} h_{t}\right)^{1-\alpha}$

$\gamma_{n} \gamma_{z} k_{t+1}=(1-\delta) k_{t}+i_{t}$

where we have defined: $\beta \equiv \beta^{*} \gamma_{z}^{\mu(1-\sigma)-1}$.

We therefore have six equations in the paths of $i_{t}, c_{t}, y_{t}, \eta_{t}, h_{t}$ and $k_{t+1}$. This is for any paths of productivity, $A_{t}$, and the degree of violation of property rights, $\theta_{t}$. The steady state solution of this system is reported in Appendix A.

\subsection{A shock to property rights: the mechanism}

In this setup, a shock to $\theta_{t}$, as already discussed in section 2 , represents changes in the institutional structure of the economy that affect the degree of protection of property rights. For example, a decrease in $\theta_{t}$ (e.g. in the form of better policing or a better legal system, such as an improvement of the regulation of the banking system and transparent bankruptcy laws) reduces the contestable prize available to 
individuals for extraction (see (3)). This in turn increases the returns to legal activities (see (8a)-(8b)), thus improving the incentives to work and invest (see (10a)-(10c)), and eventually affects the efficiency with which factor inputs are used, i.e. the productivity of the economy. This can be easily seen by substituting (10b) in (10e). Hence, a shock to $\theta_{t}$ affects productivity, so that the economic effects of a shock to property rights should have some of the characteristics of a total factor productivity shock. However, by working through the additional channel discussed above, a shock to property rights has also direct effects on factor inputs.

\section{Calibration and solution}

We calibrate the model to annual data for Mexico, for 1980-2005. The data are obtained from the OECD Economic Outlook database (no. 81), the OECD Main Economic Indicators and INEGI (see Appendix B for more details).

\subsection{Calibration and long-run results}

Since income from black market and illegal activities is not recorded in the data, we focus on extraction activities that generate income that passes though a market transaction and thus is recorded in the data. The examples of extraction activities that result from weak protection of property rights presented above in section 2 for Mexico clearly fit this category. In addition, we have assumed that rent seeking of this form takes place while at work, which implies that hours in the data include such rent-seeking activities. Hence, we assume that the economic data include the activities and outcomes of rent seeking related to weak protection of property rights.

We report in Tables 2 and 3 average values in the data, calibrated parameter values, and the resulting long-run solution. Table 3, column 1, reports the average values of $c / y, i / y$, and $h$ in the data. We assume that

[Tables 2 and 3 here]

Some parameter values in Table 2 are set on the basis of a priori information. Following usual practice, the curvature parameter in the utility function $(\sigma)$ is set equal to 2 so that the implied intertemporal elasticity of substitution is 0.5 (see e.g. Kehoe and Ruhl (2005) and Aguiar and Gopinath (2007)). Using working age 
population for Mexico, we calculate the population growth rate as $\gamma_{n}=1.026$. The capital depreciation rate $\delta^{p}$, is set equal to 0.06 (see e.g. Kehoe and Ruhl, 2005). Following Kydland (1995), we set $\mu$ (the weight given to consumption relative to leisure in the utility function) equal to the average value of $h_{t} \cdot{ }^{13}$ Both $Z_{0}$ (the initial level of technical progress) and $A_{0}$ (the level of long-run aggregate productivity) are scale parameters and are normalized to one (see also e.g. King and Rebelo, 1999). The growth rate of the exogenous labor augmenting technology, $\gamma_{z}$, is set to the average income growth rate of the world leader and neighbor USA. This is 1.025, using Penn World Tables data for 1960-2002. We finally set $\alpha=0.4$, as Garcia-Verdu (2005) calculates the capital share in income to be around $40 \%$ in Mexico.

Given the parameters and data averages above, we can use the first order condition with respect to labor (equation (10a)) to calibrate the long-run value of the exogenous process for the degree of protection of property rights. This gives a value of $\theta_{0}=0.2464$, which implies that $24.64 \%$ of the income produced in the Mexican economy is extracted because of weak property rights. Also, equation (10f) implies that the capital stock, as a share of output is $k / y=1.3775$. This number is lower than the values typically reported for developed economies, because the investment to output ratio is lower in Mexico. Then, the Euler equation (10c) implies $\beta=0.8629$. This number is smaller than the values typically employed in DSGE models and results, in our calibration, from the low investment to output (and hence capital to output) ratio in the data. The fact that an economy with weak property rights is associated with lower investment and a lower rate of time preference is not surprising. As said above, the theoretical and empirical literature on the quality of institutions has linked weak property rights to lower investment and shorter time horizons.

Table 3 reports the resulting long-run solution. Among other things, the longrun solution gives $\eta=0.6475$. Thus, in the long run of our economy, individual agents allocate only $64.75 \%$ of their effort time to productive work, while the rest

\footnotetext{
${ }^{13}$ As said above, we assume that extraction activities take place while at work, so that the employment data contain extraction time as well. Leisure then is the remainder of the time endowment, net of both extraction and work activities. Therefore, $H_{t}$ and hence $L_{t}=1-H_{t}$, are observable, even though the breakdown of hours data to productive work and rent seeking activities is not observed. Following Kydland (1995), the weight given to leisure in the utility function, $1-\mu$, should reflect the average leisure time in the data, which can be calculated using hours data. In other words, assuming that employment statistics contain extraction allows us to use Kydland's approach for Mexican data.
} 
goes to extractive activities. As a result, they grab $24.64 \%$ of the economy's income. ${ }^{14}$

\subsection{Linearized Decentralized Competitive Equilibrium}

We linearize (10a)-(10f) around the long-run solution (see Appendix A for the long run). Define $\hat{x}_{t} \equiv\left(\ln x_{t}-\ln x\right)$, where $x$ is the model consistent long-run value of a variable $x_{t}$. It is then straightforward to show that the linearized DCE is a system $E_{t}\left[A_{1} \hat{x}_{t+1}+A_{0} \hat{x}_{t}+B_{1} \hat{z}_{t+1}+B_{0} \hat{z}=0\right]$, where $\hat{x}_{t} \equiv\left[\hat{i}_{t}, \hat{c}_{t}, \hat{y}_{t}, \hat{\eta}_{t}, \hat{h}_{t}, \hat{k}_{t}\right]^{\prime}, \quad \hat{z}_{t} \equiv\left[\hat{A}_{t}, \hat{\theta}_{t}\right]^{\prime} \quad$ and $A_{1}, A_{0}, B_{1}, B_{0}$ are constant matrices of dimension $6 x 6,6 x 6,6 x 2$ and $6 x 2$ respectively. The elements of $\hat{z}_{t}$ follow the $A R(1)$ processes in (9a)-(9b). Thus, we have a linear first-order stochastic difference equation system in six variables, out of which one is predetermined $\left(\hat{k}_{t}\right)$ and five are jump $\left(\hat{i}_{t}, \hat{c}_{t}, \hat{y}_{t}, \hat{\eta}_{t}, \hat{h}_{t}\right)$. To solve it, we use the solution methodology in Klein (2000). We report that, when we use the calibrated values in Table 1, all eigenvalues are real and there is one eigenvalue with absolute value less than one, so that the model exhibits saddle-path stability.

\section{Predictions of the model}

In this section we examine the long run implications of the model and its dynamic responses after temporary shocks. This will help to contextualize the workings of the model relative to the relevant theoretical literature and empirical evidence.

\subsection{Long-run effects of institutions}

We first evaluate qualitatively the model, by comparing its long-run predictions to empirical evidence. A sensitivity analysis of the long run solution with respect to changes in the degree of violation of property rights, $\theta_{0}$, can be seen in Figure 1.

\section{[Figure 1 here]}

We first observe that weaker property rights (measured by a higher value of $\theta_{0}$ ) work as a disincentive for productive activities, as they result in a lower fraction

\footnotetext{
${ }^{14}$ Note that previous estimates of the size of rent seeking activities for both industrialized and developing countries, based on partial equilibrium and proxy calculations, (see e.g. Mueller, 2003, p. 355 , for a review) have provided similarly high or even higher results.
} 
of effort time allocated to productive work, $n$, lower productive time, $n h$, and lower investment. Therefore, worse incentives result in lower output being produced. These features are consistent with the empirical evidence using averages from a number of countries, as discussed in section 2, namely that weaker institutions are related to a misallocation of resources, lower investment and output. Worse institutions are bad for macroeconomic outcomes.

The above movements also imply a lower capital to output ratio, a fall in the investment to output ratio and an increase in the consumption to output ratio. Importantly, an increase in $\theta_{0}$ implies a decrease in both leisure time and consumption, which, via equation (2) results in a fall in utility in the long run. Therefore, worse institutions are also bad for welfare.

\subsection{Impulse response functions for Mexico}

We next compute the responses of the key endogenous variables (measured as deviations from their model-consistent long run value) to unit shocks to the exogenous processes of aggregate productivity $\left(A_{t}\right)$, and degree of protection of property rights $\left(\theta_{t}\right) \cdot{ }^{15}$ We also include the reactions of the interest rate (denoted as $r k$ ), the wage rate (denoted as $w$ ) and labor productivity (denoted as $y / h$ ), as they reflect incentives for the households to invest and work, and therefore help to explain the movement of the key endogenous variables. Results are reported in Figures $2 \mathrm{a}$ and $2 \mathrm{~b}$ respectively.

[Figures $2 \mathrm{a}$ and $2 \mathrm{~b}$ here]

Figure 2a reports the effects of a temporary shock to aggregate productivity, $A_{t}$. An increase in $A_{t}$ increases income and this supports a rise in both current and via consumption smoothing - future consumption. Since leisure is also a normal good, both current and future leisure have the tendency to follow consumption, namely to rise (or equivalently $h_{t}$ to fall). Nevertheless, a higher $A_{t}$ also raises labor productivity, the real wage, as well as the contestable prize for rent-seekers (via the increase in output). This, in turn, creates a substitution effect that works in opposite

\footnotetext{
${ }^{15}$ These responses have been generated assuming autocorrelation coefficients for the exogenous processes such that the model generated data match the persistence of output in the data (see the next section for more details).
} 
direction by increasing the total non-leisure time, $h_{t}$. Here, the latter effect dominates, so that the net effect on $h_{t}$ is positive. This is as in most of the literature (see e.g. Kollintzas and Vassilatos, 2000, as well as the references cited therein). Note that in our case the substitution effect is enhanced by the presence of the contestable prize. On the other hand, an increase in $A_{t}$ has two opposite effects on $\eta_{t}$. Namely, a negative one, which, through the increase in the contestable prize, makes private agents more aggressive leading them to allocate more time to extraction activities, and a positive one, via the increase in labor productivity. In our model, these two opposite effects completely cancel out, so that the net effect of $A_{t}$ on $\eta_{t}$ is zero (see equation (10b)). Naturally, the total efforts, allocated to both productive work and extraction activities, $\eta_{t} h_{t}$ and $\left(1-\eta_{t}\right) h_{t}$ respectively, increase.

Figure $2 \mathrm{~b}$ reports the effects of a temporary deterioration in the protection of property rights (i.e. a positive shock to $\theta_{t}$ ). These much resemble a negative productivity shock, although the responses display richer behavior, and in the case of $h_{t}$ a non-monotonic reaction. Concerning $h_{t}$, an increase in $\theta_{t}$ affects it through two channels. On one hand, since the deterioration in property rights works as a negative productivity shock, this, as explained above, tends to decrease $h_{t}$ (as well as consumption, investment, output, capital, and wages). On the other hand, extraction becomes more productive. This tends to increase $h_{t}$. The former effect is stronger initially, making $h_{t}$ decrease, but three periods after the shock the latter effect dominates. All these combined lead to the observed non-monotonic response of $h_{t}$. Concerning effort allocated to productive work, an increase in $\theta_{t}$ exerts a negative effect on $\eta_{t}$. This happens because both the reduction in labour productivity and the improvement of the extraction effectiveness tend to decrease $\eta_{t}$.

The movements in $\eta_{t}$ and $h_{t}$ after a shock to property rights are useful in helping to understand how extraction activities $\left(\eta_{t}\right)$ in this model differ to labor hoarding in the models analyzed by e.g. Burnside et al. (1993) and Burnside and Eichenbaum (1996). If $\eta_{t}$ was unobserved labor capacity utilization, it would be picked up by measured productivity (the standard Solow residual). Then, falls in $\eta_{t}$ (and hence falls in measured productivity) would imply that firms want to use less labor. In this case, they should want to decrease labor demand $\left(h_{t}\right)$ as well, so that $h_{t}$ 
should follow the movements of $\eta_{t}$ (see e.g. the impulse response analysis in Burnside and Eichenbaum (1996), p. 1168-1169). Hence, labor hoarding models cannot be consistent with falling productivity and non-decreasing $h_{t}$ over the medium run.

On the contrary, the impulse response analysis above shows that in our model, an increase in $\theta_{t}$ (which would be picked up as decreases in measured productivity) results in $\eta_{t}$ and $h_{t}$ moving in opposite directions after the first three periods (see Figure $2 b$ ). In other words, lower productivity (and lower labor capacity utilization) can be consistent in our model with increased $h_{t}$ over the medium run. Actually, as shown above in sub-section 5.1, a permanent deterioration in the degree of property rights (and hence a permanent deterioration in productivity), in the form of an increase in $\theta_{0}$, results in higher $h$ in the long run.

[Figure 3 here]

This difference in the behavior of $h_{t}$ in the medium run is important as it makes our model consistent with the Mexican experience in labor hours. As noted by Bergoeing et al. (2002b), labor hoarding models cannot account for the Mexican experience of falling productivity for a sustained period that is not accompanied by a decreasing labor input. Indeed, as can be seen in Figure 3, there has been a continuous drop in TFP in Mexico over the 80s and until the mid-90s, whereas at the same time, labor hours have not decreased (see also figure 14 in Bergoeing et al., 2002b). ${ }^{16}$ These movements cannot be explained by either the basic RBC model or labor hoarding models, which predict that labor hours should follow TFP. On the contrary, in the model of extraction activities triggered by weak property rights that we have presented here, sustained lower productivity (and lower labor capacity utilization) can be consistent with non-decreasing $h_{t}$, if this decrease in productivity has resulted from a deterioration in institutions. Indeed, as we discuss later, the model with weak property rights does much better in capturing the $h_{t}$ series for Mexico than the basic RBC model with full protection of property rights.

\footnotetext{
${ }^{16}$ The TFP series here is obtained as the Solow residual from a standard neoclassical production function. See the Appendix for more details regarding the data and the construction of the TFP series.
} 


\section{Property rights and second moment evaluation}

To evaluate the usefulness of allowing for weak property rights in a standard RBC model, we compare the model with weak property rights to the model with full protection of property rights, by examining whether the second moments of the model generated data match those of the actual data for Mexico. We focus on the main aggregate macro variables $y_{t}, c_{t}, i_{t}$ and $h_{t}$ for which data are available over the period 1980-2005 (see Appendix B for details on the data). Note that the model with

full protection of property rights can be obtained from the model developed here by simply "switching off" property rights problems, that is $\theta_{t}=0$ and hence $\eta_{t}=1$ at all $t$. Hence, what we define here as the model with full protection of property rights, is the basic RBC model (see e.g. King and Rebelo, 1999).

Our main aim is to investigate whether shocks to the protection of property rights help the model generate some key business cycle statistics observed in the data. In order to obtain a benchmark, we first evaluate the fit of the model with full protection of property rights vis-à-vis the data. We then evaluate the fit of the model with weak property rights. In particular, we examine whether treating property rights as the exogenous driving process for the model, without additional productivity shocks, suffices for the model to match the data well enough for property rights to be a plausible driving force. In addition, we investigate whether there can be improvements regarding the model fit - relative to the RBC model - by allowing for weak property rights.

In order to get the cyclical component of the series, we take logarithms and apply the Hodrick-Prescott filter with a smoothing parameter of 100 for both the simulated and the actual data. We study the volatility, persistence and co-movement properties of the key variables. To obtain the model-predicted moments, we simulate the model 1000 times and present the sample average of the statistics along with the $90 \%$ confidence interval. We then calculate the statistics from the actual data and examine whether the actual data statistics are within the bands predicted by the model (see e.g. Canova, 2007, chapter 7). Table 5 below summarizes the results for standard deviation while Figures 4 and 5 below present the autocorrelation functions (ACFs) and cross-correlation functions (CCFs).

We start with the model with full protection of property rights. Note that the exogenous process for the basic RBC model is the TFP process in (9a). We estimate 
the persistence and standard deviation of the unobservable technology process in (9a) by calculating the Solow residual for this model and estimating the relevant AR(1) process (see Appendix B for details). The results, reported in Table 4, show that $\rho_{A}=0.914$ and $\sigma_{A}=0.025 .{ }^{17}$ Given these, as can be seen in Table 5 below and with the exception of the relative volatility of consumption, the baseline RBC model is not doing qualitatively badly with respect to volatility vis-à-vis the data, as the simulated relative standard deviations are qualitatively similar to those of the actual data and the standard deviation of income is quantitatively similar to the data as well. Regarding consumption, Aguiar and Gopinath (2007) show that a DSGE model with shocks to the trend growth rate can reproduce this feature of the data.

[Tables 4 and 5 here]

The picture is not as good, however, when looking at ACFs and CCFs for the basic RBC model, in Figures $4 \mathrm{a}$ and $4 \mathrm{~b}$ below. In general, the RBC model tends to overestimate the persistence and cross-correlations of $y_{t}, c_{t}, i_{t}$ and the persistence of $h_{t}$ relative to those in the data, as the data statistics are generally at the lower bound or below the $90 \%$ confidence interval of the model generated statistics. The predictions are clearly off with respect to the cross-correlation functions of labor hours with the other endogenous variables. The basic RBC model, driven by TFP shocks, cannot match the second moments of $h_{t}$.

\section{[Figures $4 \mathrm{a}-4 \mathrm{~b}$ here]}

We then move on to the model with weak property rights. To illustrate the importance of weak property rights we consider the extreme scenario where the only shocks that hit the model economy are shocks to property rights. Thus, we shut down TFP shocks for this exercise. Since $\theta_{t}$ is unobservable, we choose $\rho_{\theta}$ and $\sigma_{\theta}$ so that the generated series for income match the first order autocorrelation and standard deviation of the actual series for income. Hence, having captured the basic second moments for income by both the basic RBC model and the model where property rights are the only exogenous force, we can evaluate the performance of the

\footnotetext{
${ }^{17}$ These also imply that the basic RBC model essentially matches the standard deviation and the first order autocorrelation coefficient of output in the data.
} 
two models with respect to the second moments for the rest of the variables. Matching the persistence and volatility of income in the data is achieved for $\rho_{\theta}=0.7$ and $\sigma_{\theta}=0.1$ (see Table 4). As we shall see below, using a suitable normalization of the $P R$ variable, we can obtain empirical evidence that property rights in Mexico are indeed as persistent and volatile.

As can be seen in Table 6 below, this model reproduces the empirical regularity observed in the data with respect to the correlation of the quality of institutions and the main economic variables. All the correlations between $\theta_{t}$ and income, consumption and investment are negative, implying a positive correlation between the protection of property rights and these variables (recall that increases in $P R$ imply a better quality of institutions, while an increase in $\theta_{t}$ implies a deterioration in the protection of property rights).

[Table 6 here]

The results of the experiment above regarding the second moments are reported in Table 5 above and Figures $5 \mathrm{a}-5 \mathrm{~b}$ below.

[Figure 5a-5b here]

The relative standard deviations generated by this model are qualitatively similar to those of the basic RBC model. Quantitatively, the basic RBC model is doing better with respect to $c_{t}$ and $h_{t}$, while the model with weak property rights is doing better with respect to $i_{t}$. Regarding the ACFs and CCFs for $y_{t}, c_{t}, i_{t}$, both models share the same qualitative features. However, the data statistics are always within the model predictions for the model with weak property rights, and actually quite close to the model average, whereas on the contrary, for the model with full protection of property rights this is not always the case. The biggest improvement is with respect to the labor statistics. The model still cannot match the (negative) contemporaneous correlation of $h_{t}$ with $y_{t}, c_{t}, i_{t}$ in the data, but the autocorrelation function and the lagged cross-correlations in the data are almost always within the bands predicted by the model. 
Overall, the model with shocks to property rights only does a better job in explaining business cycle statistics than the basic RBC model with technology shocks. ${ }^{18}$ This comparison suggests that it is plausible to interpret (and model) technology shocks as shocks to property rights.

\section{Technology shocks and shocks to institutions}

In this section we construct a proxy for $\theta_{t}$ by using data from ICRG for Mexico to demonstrate the workings of the model when the driving force is shocks to institutions compared to shocks to the TFP process, when the latter is approximated by the Solow residual.

\subsection{A proxy for $\theta_{t}$}

Using ICRG data on Political Risk for 1984-2005 for Mexico (see Appendix B for more details), we construct a variable that takes values between zero and one, with higher scores implying more extraction, and is normalized to have an average of 0.2464 , which is the long run value for $\theta_{t}$ as obtained from the calibration. We use this variable as a proxy for $\theta_{t}$; hence, we interpret increases in this variable as increases in the percentage of national income that private agents perceive as a contestable prize because it is not protected by institutions. This normalization is simple and intuitive. In addition, when we use this proxy for $\theta_{t}$ to obtain an estimate for the persistence and the volatility of the latter, we find that $\rho_{\theta}=0.626$ and $\sigma_{\theta}=0.09$, which are very close to the values that the model with shocks to property rights and without further shocks to productivity needs to match the second moments of the data for Mexico. ${ }^{19}$ This variable then provides some support to the argument that shocks to property rights can be behind the economic fluctuations in Mexico, as the statistical properties of the required series for $\theta_{t}$ are empirically plausible.

\footnotetext{
${ }^{18}$ We also report that we have calibrated a version of the model with weak property rights that allows for shocks to both TFP and property rights. The results (available upon request) regarding the second moments are similar to the results for the model with weak property rights where the only driving process is shocks to the protection of property rights. Hence, this model again gives a better fit to the data than the basic RBC model with full protection of property rights.

${ }^{19}$ Hence, an alternative way of viewing the normalization for the measure for $\theta_{t}$ would be that its units match the mean value of $\theta_{t}$, as implied by the model, and also that its variance is such that the model generated standard deviation of output from the model with shocks to $\theta_{t}$ only, matches the standard deviation of output in the data.
} 


\subsection{TFP as the Solow residual and as $\theta_{t}$}

We next move to examine the relationship between TFP as predicted endogenously from the basic RBC model, using the Solow residual, and TFP as predicted by the property rights model when the only driving force is the $\theta_{t}$ process, using the above proxy. The TFP for the model with full protection of property rights is obtained as:

$$
\operatorname{TFP}_{A t}=\frac{y_{t}}{k_{t}^{\alpha} h_{t}^{1-\alpha}}
$$

As discussed in subsection 3.5 above, shocks to $\theta_{t}$ show up as TFP shocks in the model with property rights. Hence, in the absence of shocks to $A_{t}$, we can normalize $A$ to one and obtain TFP as predicted by the weak protection of property rights model and our proxy for $\theta_{t}$ as:

$$
\operatorname{TFP}_{\theta t}=\left(\frac{(1-\alpha)\left(1-\theta_{t}\right)}{\theta_{t}+(1-\alpha)\left(1-\theta_{t}\right)}\right)^{1-a}
$$

In Figure 6, we present the log-deviations from trend for $T F P_{A t}$ and for $T F P_{\theta t}$ for 1984-2005 for Mexico. Both series are de-trended using the Hodrick-Prescott filter. As shown in this figure, $T F P_{\theta t}$ generally follows the movements of $T F P_{A t}$, except for the period 1996-2000, immediately after the 1995 crisis. In particular, both series are below trend in the 80s, improve to above trend in the early 90 s and fall abruptly with the 1995 crisis (although $T F P_{\theta t}$ clearly falls by much less than $T F P_{A t}$ ). Thenceforth, $T_{F P}$ does not follow $T F P_{A t}$ for the rest of the 90s. The two series essentially move together again after 2000. The general picture is consistent with the model characteristic that shocks to property rights should appear as productivity shocks.

\section{[Figure 6 here]}

In particular, looking at Figure 6, we see that there is decreased (below trend) productivity in Mexico in the second part of the 1980s. According to the model, a worsening in property rights in this period resulted in declines in productivity. This 
is consistent with the analysis in e.g. Bergoeing et al. (2002a, 2002b), as also discussed above. Then, as institutions improved in the early 1990s, productivity was above trend. The institutional shock of the political crisis of 1994-1995 is picked up by a significant worsening of property rights, which is also reflected in a worsening in productivity. Residual productivity, $T F P_{A t}$, increased immediately after the crisis, but our proxy for $\theta_{t}$ does not predict this rapid improvement. Hence, for this period, institutional shocks are not enough to explain TFP movements in Mexico. After 2000, Figure 6 suggests that we would not be far off if we explained shocks to productivity by using the PR variable for $\theta_{t}$. Overall, the evolutions in $\theta_{t}$ are consistent with the Mexican experience in institutions and, to a large extent, help to understand the movements in productivity in Mexico.

\subsection{Predicting the actual fluctuations in Mexico from shocks to property rights}

We now examine whether using our proxy for $\theta_{t}$, as the driving force for productivity in Mexico, can help with the data in order to account for the Mexican cycle.

We work as follows. First, we plot the log-deviations from trend for the actual $y_{t}, c_{t}, i_{t}$ and $h_{t}$ series for 1984-2005 in Mexico (all series are de-trended using the Hodrick-Prescott filter). These are indicated in Figures 7a-7d by the lines with circles. Then, we feed the basic RBC model the actual realizations of the $T F P_{A t}$ process for the same period and plot the de-trended data for $y_{t}, c_{t}, i_{t}$ and $h_{t}$ generated by this model. These are indicated by the lines with diamonds in Figures 7a-7d. As can be seen, the generated series for output closely matches the actual series. This is not surprising, given that the Solow residual is constructed endogenously to reflect the difference between the changes in output and the changes in inputs, and thus to capture shocks to output. The generated series for the other variables are not as good for the second part of the 80s, but generally follow the actual series in the other two decades. In particular, labor hours are above trend between 87-91, whereas the model predicts below trend hours. This is related to the discussion in 5.2. It is a result of the theoretical prediction of the RBC model that labor hours should always follow the movements in productivity. Therefore, since productivity was below trend in this period, so should labor hours be. 
[Figures 7a-7d here]

To illustrate how allowing for weak property rights can help with the data, we examine the predictions of the model with weak protections of property rights. First, we assume that there are no technology shocks in Mexico and that the only force driving the business cycle is shocks to the degree of protection of property rights, as captured by the process for $\theta_{t}$ constructed with the $P R$ variable. Then, we feed this model the actual realizations of the $\theta_{t}$ process, without any further unobserved technology shocks, and plot the series generated by this experiment. These are the lines with crosses in Figures 7a-7d. As can be seen, the model generated data for output are not far from the actual data until the 1995 crisis, and then again after 2000. This again should not be particularly surprising, given that, as we saw earlier, the movements in $\theta_{t}$ essentially correspond to the TFP movements in these two periods, and movements in TFP are highly correlated with movements in output in the data (see also e.g. Bergoeing et al., 2002b).

An important benefit from viewing $\theta_{t}$ as the driving process is in matching the behavior of the other three series $c_{t}, i_{t}$ and especially $h_{t}$ in the period until the 1995 crisis. In particular, investment, over the whole 1984-1994 period, and consumption and hours in the 80 s are clearly better predicted by the model with weak property rights and the channel it assumes for the shocks to property rights to affect the economy. The success in matching $h_{t}$ for the $80^{\prime} \mathrm{s}$ is the result of the modelling assumption that agents use their work time to engage in extraction activities as well. Hence, these results indicate that one way to explain the employment statistics is to assume that they include non-productive, rent-seeking activities as well.

We also examine the predictions of the model with weak property rights, when we allow for both shocks to the quality of institutions and unobserved productivity shocks. In this case, we re-calculate the Solow residual (see Appendix B for more details). Note that this Solow residual is net of the effect of shocks to property rights, as captured by $\theta_{t}$.

The predictions from this model are shown in Figures 7a-7d as the lines with the stars. As expected, the predictions obtained lie between those of the two polar cases where the only driving forces were either unobserved technology or 
institutions. In general, the fit of the model in this case has improved compared to the model with full protection of property rights, especially for the period up to the debt crisis of 1995. Decomposing the unobserved technology shock to a part that is explained by shocks to the quality of institutions has helped the neoclassical model with the data, especially for the series for output and hours worked. The improvement is not big, but this is because the basic neoclassical model, when driven by unobserved TFP, does a good job with the data to start with.

To summarize the fit of the different models with respect to the data, we present in Table 7 a descriptive measure of model fit, the sum of squared deviations (SSD) of each model's prediction from the actual data, for each variable. To highlight the difference between the models' fit before and after the debt crisis of 1995, we also report the sum of squared deviations for the period 1984-1994 (i.e. for the first half of our sample). Two important results emerge. First of all, the fit of the model with weak property rights when the only exogenous force is $\theta_{t}$ shocks (the second column in Table 7), as compared to the two other models, improves dramatically when we look at the 1984-1994 period. In particular, the SSD obtained from this model for the 1984-1994 period is smaller than the SSD obtained from the other models for every variable in Table 7. Therefore, assuming that for this period the shocks that hit the Mexican economy were shocks to institutions receives clear empirical support. Evidently, this result also implies that for the period after the 1995 debt crisis, other shocks and channels, not modelled here, become very important, so that the predictive power of the model with shocks to property rights only is reduced. However, we still get a better fit for the series for hours for the whole period by assuming that TFP shocks are shocks to the quality of institutions.

\section{[Table 7 here]}

Secondly, allowing for a part of the unobserved TFP shock in the data to come from shocks to institutions, as we do to obtain the results in column 3, generally improves the fit of the neoclassical model (compare column 3 to column 1). With the exception of consumption and investment for the whole period and investment for the 1984-1994 period, the SSD in column 3 is smaller than the SSD in column 1. Hence, there are gains by allowing for shocks to institutions, even if these are not the only exogenous force driving the economy. 
The model with property right shocks only cannot fit the data in the mid and late nineties. Essentially, there is a structural break in the predictive power of the model, suggesting that the effect of shocks to the quality of institutions on economic fluctuations for that period is overshadowed by other shocks. In the period during and after the debt crisis of 1995, movements in current accounts, capital flows and exchange rates are also a very important part of the story (see e.g. Kehoe and Ruhl, 2007, and Meza and Quintin, 2007), that we do not model. It would be a very interesting extension to incorporate institutional mechanisms in richer models, especially open economy setups, to try to account for more stylized facts of emerging economies. In particular, it would first be interesting to examine under what conditions institutional shocks can lead to "sudden stop" crises, i.e. to stops in capital inflows in a country. Indeed, the Mexican experience of 1994-1995 suggests that a politico-institutional shock preceded the debt crisis of 1995, as discussed above in section 2. Institutional shocks can affect the present discounted value of the county's assets by reducing income in the long run, as is the case in the model presented here. Hence, when countries face a collateral constraint on borrowing, institutional shocks can affect the maximal amount of borrowing (see e.g. equation (3) in Chari et al., 2005) and thus lead to sudden drops in capital inflows. In addition, it would be interesting to examine whether allowing for frictions caused by institutional problems, like weak property rights, can help the neoclassical model match the behavior of the economy after shocks in the form of a "sudden stop". Accounting for the effects of "sudden stops" on income is not an easy task using the neoclassical model, as Chari et al. (2005) have demonstrated that this model predicts an increase and not a fall in output after such a shock. Here, by using a simple political economy extension to the benchmark, closed economy, neoclassical model we show that this can be useful both in characterizing the nature of (some) shocks and in explaining some stylized facts.

\section{Conclusions}

We incorporated weak property rights into an otherwise standard RBC model. The model was then calibrated to Mexico, where movements in productivity in the data are associated with changes in institutions. We found that allowing for weak property rights can contribute to understanding the Mexican experience in business cycles. Therefore, interpreting unobserved productivity shocks as shocks to the quality of institutions can help to explain economic fluctuations. 
The simple model presented here cannot account for all the empirical regularities of the Mexican economy. Therefore, it would be an interesting extension to incorporate weak property rights, or other appropriate political economy considerations, in richer dynamic stochastic general equilibrium setups, to examine whether this can help to better explain economic fluctuations in emerging markets. 


\section{Appendices}

\section{Appendix A: Long-run equilibrium of (10a)-(10f)}

In the long run, there are no shocks and variables remain constant. Thus, $x_{t+1}=x_{t}=x_{t-1} \equiv X$, where variables without time subscript denote long-run values. Equations (10a)-(10f) imply:

$$
\begin{aligned}
& \frac{c}{(1-h)}=\frac{\mu}{(1-\mu)}\left(\frac{\left((1-\alpha)\left(1-\theta_{0}\right)+\theta_{0}\right) y}{h}\right) \\
& \eta=\frac{(1-\alpha)\left(1-\theta_{0}\right)}{\theta_{0}+(1-\alpha)\left(1-\theta_{0}\right)} \\
& 1=\beta\left[1-\delta+\frac{\alpha\left(1-\theta_{0}\right) y}{k}\right] \\
& y=c+i \\
& y=A_{0} k^{\alpha}(\eta h)^{1-\alpha} \\
& \gamma_{n} \gamma_{z} k=(1-\delta) k+i
\end{aligned}
$$

which is a system in $y, k, c, i, h$ and $\eta$.

\section{Appendix B: Data appendix}

\section{A) An empirical proxy for $\theta_{t}$}

The ICRG dataset includes many measures associated with investment risk in an international sample of countries. These data are compiled by a private firm, Political Risk Services. The ICRG dataset comprises 22 variables in three subcategories of risk: political, financial and economic. Many economists (see e.g. the papers reviewed in section 2 in the paper) have used sub-components of the Political Risk rating as a measure of the quality of institutions. For instance, the well-known Knack and Keefer (1995) IRIS dataset contains six such variables: corruption, rule of law, bureaucratic quality, expropriation risk, repudiation of government contracts and ethnic tensions. The disadvantage of this dataset is that it does not cover the whole period we work with, as it is available for 1984-1997. Hence, we use the following components of Political Risk, available annually from 1984-2005, to construct a measure of the quality of institutions: bureaucratic quality, democratic accountability, ethnic tensions, law and order, religious tensions, military in politics, corruption, external 
conflict (including war, cross-border conflict and foreign pressures), internal conflict (including civil war, political violence and civil disorder) and investment profile (including contract expropriation, profits repatriation and payment delays). Essentially, these measures subsume and extend the IRIS measures. They provide annual values for indicators of the quality of governance, corruption, security of property and overall of the quality of institutions that protect property rights (see http://www.prsgroup.com/ICRG_Methodology.aspx for more details on the ICRG index and its components). Note how the examples of institutional problems for Mexico that our modeling can capture, as we discussed above in section 2 (corruption, rent seeking, political instability, civil disorder, quality of regulation, bankruptcy laws, privatization procedures) are related to the ICRG variables we use. Although other proxies of institutions are available, we prefer the ICRG index because of its time series dimension. In any case, we note that the empirical proxies for weak institutions tend to be highly correlated (see e.g. Acemoglu et al. 2001, p. 1370 and 2003, p. 68).

We sum the components (the sum takes values between 0-76) and denote this sum as the $P R$ variable, which we use in section 2 . Higher values indicate better institutional quality. To obtain a proxy for $\theta_{t}$ using the $P R$ variable, we first re-scale it to the $[0,1]$ interval. We then assume that this is a proxy for $1-\theta_{t}$, the degree of protection of property rights. This then implies that $\theta_{t}$ is one minus the rescaled $P R$ variable. This proxy yields an average of 0.2755. Although this transformation is intuitive, we need to be careful with the units of measurement, as the standard deviation depends on them. In particular, we want this proxy for $\theta_{t}$ to be expressed in units that are consistent with the model. From our calibration exercise in section 4, we have estimated the long run value of $\theta_{t}$ to be 0.2464 . We hence standardize the series by multiplying each observation by the factor $\frac{0.2464}{0.2755}$, so that its values are consistent with the model.

\section{B) National accounts data}

We use annual data. For Mexico, the data come from the OECD Economic Outlook database (no. 81) for income, consumption and investment. We use GDP, private consumption and private investment in constant prices and divide by population between 14 and 65 to obtain the per capita values. For the other countries, in Table 1, 
we use the respective per capita WDI series, as many of those counties are not OECD members.

Data on actual hours worked are not available for many of those countries for the time period we are interested in. For Mexico, in particular, there are data available on hours worked from 1994 onwards from the International Labor Organization (ILO) databases (the source being INEGI (Instituto Nacional de Estadistica Geografia e Informatica)). In order to obtain a proxy for $h_{t}$ we divide total hours worked by total hours available for work or leisure. To obtain total hours, we assume, following e.g. Ho and Jorgenson (2001) that there are 14 hours available for work or leisure on a daily basis, as 10 hours are required for physiological needs. The average between 1991 and 2005 for this $h_{t}$ series for Mexico is 0.467 .

Since this series is available for the last 14 years only, we follow Bergoeing et al. $(2002 \mathrm{a}, 2002 \mathrm{~b})$ and construct an alternative series for labor input, by calculating the ratio of an index on hours worked in manufacturing to an index of employment in manufacturing. Both indices are available from the OECD Main Economic Indicators (MEI) and extend back to 1980. This index takes the value 1 in the year 2000. We scale the index, as in Bergoeing et al. (2002a, 2002b), so that the hours worked in 1980 is 45 . We then obtain a proxy for $h_{t}$ by dividing total hours worked by total hours available for work or leisure. To obtain total hours, we assume again that there are 14 hours available for work or leisure on a daily basis. This series for $h_{t}$ has an average of 0.46 . Thus, essentially, both available series for $h_{t}$ give the same average, which we use to calibrate the model. We use the OECD MEI data for the $h_{t}$ series required to calculate the statistical properties of $h_{t}$ in the data, and to calculate the Solow residual, as it is available for the whole time period.

\section{C) Solow residuals}

For the basic neoclassical model we obtain the Solow residual as:

$$
\ln A_{t}=\ln y_{t}-\alpha * \ln k_{t}-(1-\alpha) * \ln h_{t}
$$

where $y_{t}$ and $k_{t}$ are defined in per efficiency units terms, $h_{t}$ is the labor input and $\alpha=0.4$. To construct $k_{t}$ we use the investment series in the data for 1980-2005, assume a depreciation rate of $6 \%$ and choose the initial value for capital so that the average of the ratio of the constructed $k_{t}$ series over $y_{t}$ matches the implied long run $k / y$ ratio from (A.1f). The per capita capital and income series are de-trended by 
dividing by a series that is growing by $1.025 \%$, to obtain $k_{t}$ and $y_{t}$. We use the series for $h_{t}$ obtained from the OECD MEI data as described above.

For the model with both an unobserved exogenous technology process and an exogenous property rights process, we calculate the Solow residual that is adjusted for the effects of $\theta_{t}$. In particular, we substitute (10b) into (10e) and calculate the required process as:

$$
\ln A_{t}=\ln y_{t}-\alpha * \ln k_{t}-(1-\alpha) * \ln h_{t}-(1-\alpha) * \ln \left(\frac{(1-\alpha)\left(1-\theta_{t}\right)}{\theta_{t}+(1-\alpha)\left(1-\theta_{t}\right)}\right)
$$

by using the data for $y_{t}, k_{t}, h_{t}$ and $\theta_{t}$ as above. 
Table 1: The quality of institutions and main macroeconomic variables

\begin{tabular}{|c|c|c|c|c|}
\hline Country & $\begin{array}{c}\text { Standard } \\
\text { Deviation } \\
(P R)\end{array}$ & $\begin{array}{c}\text { Correlation } \\
(\overline{P R}, \bar{y})\end{array}$ & $\begin{array}{c}\text { Correlation } \\
(\overline{P R}, \bar{c})\end{array}$ & $\begin{array}{c}\text { Correlation } \\
(\overline{P R}, \bar{i})\end{array}$ \\
\hline \multicolumn{5}{|c|}{ Emerging Economies } \\
\hline Argentina & 7.405 & 0.692 & 0.690 & 0.676 \\
\hline Brazil & 2.994 & 0.199 & -0.452 & 0.061 \\
\hline Chile & 12.817 & 0.608 & 0.591 & 0.686 \\
\hline Colombia & 4.888 & 0.247 & 0.433 & 0.301 \\
\hline Costa Rica & 5.774 & 0.047 & 0.117 & 0.063 \\
\hline Ecuador & 2.272 & 0.511 & 0.517 & 0.290 \\
\hline Indonesia & 9.228 & 0.856 & 0.540 & 0.753 \\
\hline Korea & 4.893 & 0.315 & 0.361 & 0.287 \\
\hline Malaysia & 4.339 & 0.772 & 0.774 & 0.820 \\
\hline Mexico & 2.907 & 0.169 & 0.961 & 0.851 \\
\hline Peru & 10.715 & 0.216 & 0.218 & 0.287 \\
\hline Romania & 9.549 & 0.081 & 0.095 & 0.344 \\
\hline Thailand & 8.360 & 0.405 & 0.435 & 0.341 \\
\hline Uruguay & 6.813 & 0.071 & 0.235 & 0.179 \\
\hline Venezuela & 8.109 & 0.438 & 0.179 & 0.273 \\
\hline Averages & 6.738 & 0.375 & 0.379 & 0.414 \\
\hline \multicolumn{5}{|c|}{ Developed Economies } \\
\hline Australia & 2.060 & -0.191 & -0.404 & -0.101 \\
\hline Austria & 2.357 & -0.261 & -0.085 & -0.337 \\
\hline Belgium & 2.335 & -0.319 & -0.285 & -0.265 \\
\hline Canada & 1.961 & 0.237 & 0.395 & 0.407 \\
\hline Denmark & 1.873 & 0.515 & -0.193 & 0.367 \\
\hline Spain & 6.004 & -0.366 & -0.280 & -0.441 \\
\hline Finland & 2.750 & 0.626 & 0.436 & 0.569 \\
\hline France & 3.277 & -0.207 & -0.357 & -0.261 \\
\hline Germany & 1.316 & 0.345 & 0.042 & 0.190 \\
\hline Greece & 8.489 & -0.334 & -0.040 & -0.455 \\
\hline Ireland & 4.329 & -0.188 & -0.360 & -0.036 \\
\hline Italy & 3.030 & -0.143 & -0.292 & -0.198 \\
\hline Japan & 3.610 & 0.053 & 0.234 & 0.035 \\
\hline Netherlands & 2.361 & 0.890 & 0.895 & 0.829 \\
\hline Norway & 2.380 & -0.324 & -0.348 & -0.276 \\
\hline N. Zealand & 1.658 & 0.687 & 0.466 & 0.449 \\
\hline Portugal & 7.560 & 0.099 & 0.103 & 0.445 \\
\hline Sweden & 2.116 & 0.257 & 0.194 & 0.246 \\
\hline UK & 2.135 & -0.119 & -0.280 & -0.159 \\
\hline USA & 2.977 & 0.215 & -0.053 & 0.556 \\
\hline Averages & 3.229 & 0.074 & -0.010 & 0.078 \\
\hline
\end{tabular}

Notes: $y, c, i$ are defined in per capita terms. A bar above the variable implies that this is detrended (using the Hodrick-Prescott filter). See Appendix B for more details on the data. 
Table 2: Calibration

\begin{tabular}{|c|c|c|}
\hline $\begin{array}{c}\text { parameter } \\
\text { or } \\
\text { Variable }\end{array}$ & Description & value \\
\hline$\alpha$ & capital share in production & 0.4 \\
\hline$\delta^{p}$ & capital depreciation rate & 0.06 \\
\hline$A_{0}$ & long run productivity & 1 \\
\hline$\gamma_{z}$ & growth rate of labor augmenting technology & 1.025 \\
\hline$\mu$ & consumption weight in utility function & 0.46 \\
\hline$\sigma$ & curvature parameter in utility function & 2 \\
\hline$\gamma_{n}$ & Population growth rate & 1.026 \\
\hline$\beta$ & time discount factor & 0.8629 \\
\hline$\theta_{0}$ & extraction technology parameter & 0.2464 \\
\hline
\end{tabular}

Table 3: Data averages and long-run solution

\begin{tabular}{|c||c||c|c|}
\hline variable & Description & $\begin{array}{c}\text { data } \\
\text { averages }\end{array}$ & $\begin{array}{c}\text { Long-run } \\
\text { solution }\end{array}$ \\
\hline$c / y$ & consumption to output ratio & 0.6985 & 0.8462 \\
\hline$i / y$ & investment to output ratio & 0.1538 & 0.1538 \\
\hline$h$ & hours at work & 0.46 & 0.4129 \\
\hline$n$ & $\begin{array}{c}\text { fraction of hours at work } \\
\text { allocated to productive work }\end{array}$ & $\mathrm{Na}$ & 0.6475 \\
\hline$k / y$ & capital to output ratio & $\mathrm{Na}$ & 1.3775 \\
\hline
\end{tabular}

Table 4: Exogenous processes

\begin{tabular}{|c||c|c|}
\hline parameter & $\begin{array}{c}\text { full protection of } \\
\text { property rights }\end{array}$ & $\begin{array}{c}\text { weak } \\
\text { property rights }\end{array}$ \\
\hline$\rho_{A}$ & 0.914 & 0 \\
\hline$\sigma_{A}$ & 0.025 & 0 \\
\hline$\rho_{\theta}$ & 0 & 0.7 \\
\hline$\sigma_{\theta}$ & 0 & 0.1 \\
\hline
\end{tabular}


Table 5: Relative volatility, $x \equiv s_{x} / s_{y}$

\begin{tabular}{|c||c|c|c|}
\hline$x$ & data & $\begin{array}{c}\text { full protection of } \\
\text { property rights }\end{array}$ & $\begin{array}{c}\text { weak } \\
\text { property rights }\end{array}$ \\
\hline$c$ & 1.340 & $\begin{array}{c}0.691 \\
{[0.623,0.718]}\end{array}$ & $\begin{array}{c}0.452 \\
{[0.356,0.548]}\end{array}$ \\
\hline$i$ & 5.862 & $\begin{array}{c}2.925 \\
{[2.820,3.030]}\end{array}$ & $\begin{array}{c}4.675 \\
{[4.316,5.034]}\end{array}$ \\
\hline$h$ & 0.288 & $\begin{array}{c}0.226 \\
{[0.216,0.235]}\end{array}$ & $\begin{array}{c}0.129 \\
{[0.114,0.143]}\end{array}$ \\
\hline$S_{y}$ & 0.028 & 0.027 & 0.028 \\
\hline
\end{tabular}

Note: The columns for the model generated relative volatilities report the average and the $90 \%$ confidence interval below that.

Table 6: Correlations between $\theta_{t}$ and main macroeconomic variables

\begin{tabular}{|c|c|c|}
\hline $\begin{array}{c}\text { Correlation } \\
\left(\bar{\theta}_{t}, \bar{y}_{t}\right)\end{array}$ & $\begin{array}{c}\text { Correlation } \\
\left(\bar{\theta}_{t}, \bar{c}_{t}\right)\end{array}$ & $\begin{array}{c}\text { Correlation } \\
\left(\bar{\theta}_{t}, \bar{i}_{t}\right)\end{array}$ \\
\hline-0.967 & -0.655 & -0.999 \\
\hline
\end{tabular}

Notes: See notes in Table 1.

Table 7: Sum of squared deviations for model predictions

Full time period (1984-2005)

\begin{tabular}{|c|c|c|c|}
\hline $\begin{array}{c}\text { Sum of squared } \\
\text { deviations } \\
\text { between actual } \\
\text { data and model } \\
\text { predictions }\end{array}$ & $\begin{array}{c}\text { Full } \\
\text { protection of } \\
\text { property } \\
\text { rights (basic } \\
\text { RBC model) }\end{array}$ & $\begin{array}{c}\text { Weak } \\
\text { protection of } \\
\text { property } \\
\text { rights }\left(\theta_{t}\right. \\
\text { shocks only) }\end{array}$ & $\begin{array}{c}\text { Weak } \\
\text { protection of } \\
\text { property } \\
\text { rights }\left(\theta_{t} \text { and }\right. \\
\text { TFP shocks) }\end{array}$ \\
\hline for $y_{t}$ & 0.527 & 2.591 & 0.503 \\
\hline for $c_{t}$ & 2.243 & 3.5110 & 2.742 \\
\hline for $i_{t}$ & 21.754 & 59.299 & 26.927 \\
\hline for $h_{t}$ & 0.295 & 0.109 & 0.188 \\
\hline
\end{tabular}

Until the debt crisis (1984-1994)

\begin{tabular}{|c|c|c|c|}
\hline $\begin{array}{c}\text { Sum of squared } \\
\text { deviations } \\
\text { between actual } \\
\text { data and model } \\
\text { predictions }\end{array}$ & $\begin{array}{c}\text { Full } \\
\text { protection of } \\
\text { property } \\
\text { rights (basic } \\
\text { RBC model) }\end{array}$ & $\begin{array}{c}\text { Weak } \\
\text { protection of } \\
\text { property } \\
\text { rights }\left(\theta_{t}\right. \\
\text { shocks only) }\end{array}$ & $\begin{array}{c}\text { Weak } \\
\text { protection of } \\
\text { property } \\
\text { rights }\left(\theta_{t} \text { and }\right. \\
\text { TFP shocks) }\end{array}$ \\
\hline for $y_{t}$ & 0.452 & 0.361 & 0.439 \\
\hline for $c_{t}$ & 1.887 & 1.266 & 2.204 \\
\hline for $i_{t}$ & 15.158 & 9.834 & 12.253 \\
\hline for $h_{t}$ & 0.210 & 0.057 & 0.111 \\
\hline
\end{tabular}

Note: For ease of presentation, the sum of squared deviations has in each case been multiplied by 100 . 
Figure 1: Long run effects of changes in $\theta_{0}$
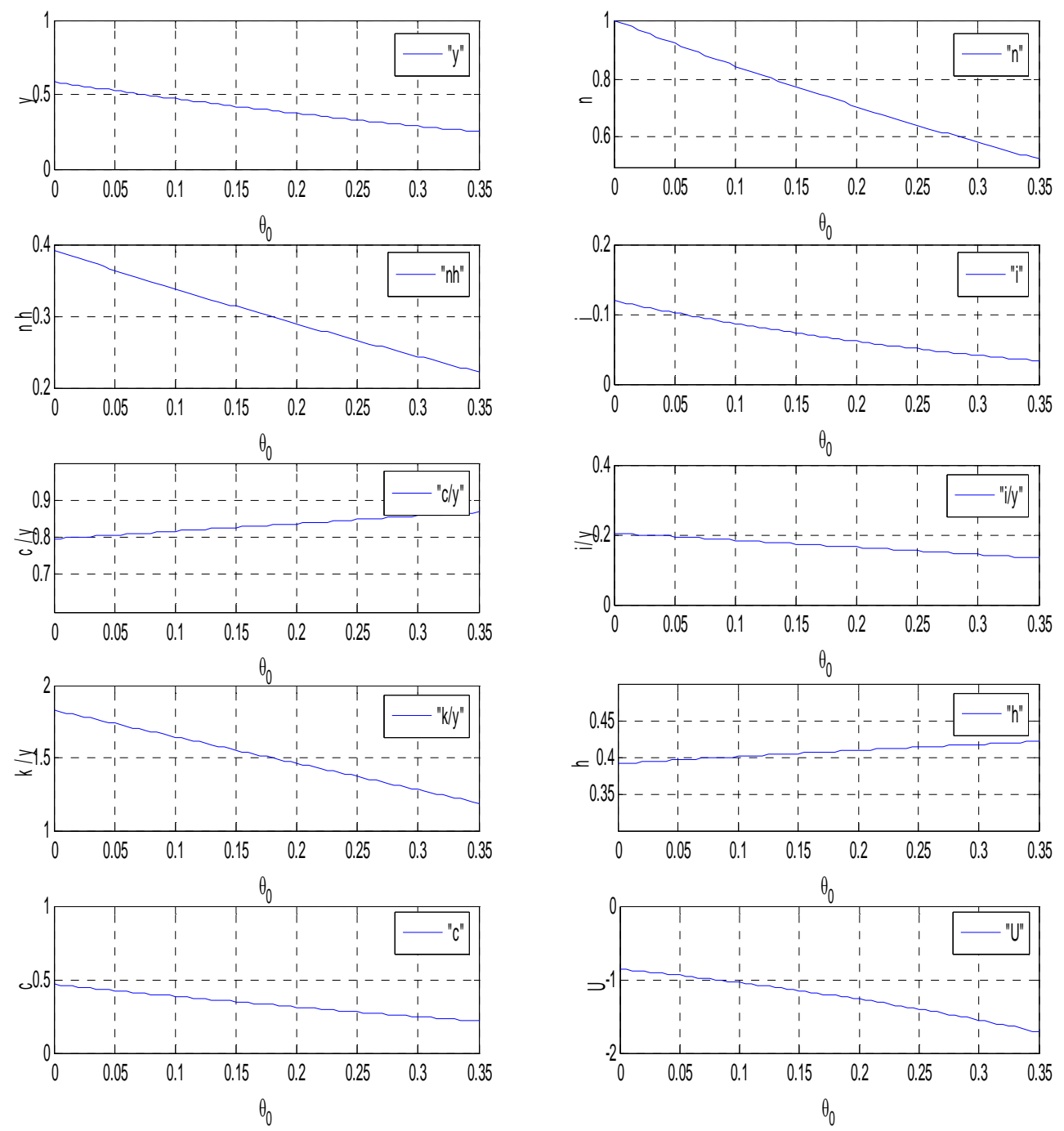
Figure 2a: Impulse responses to shocks to $A_{t}$
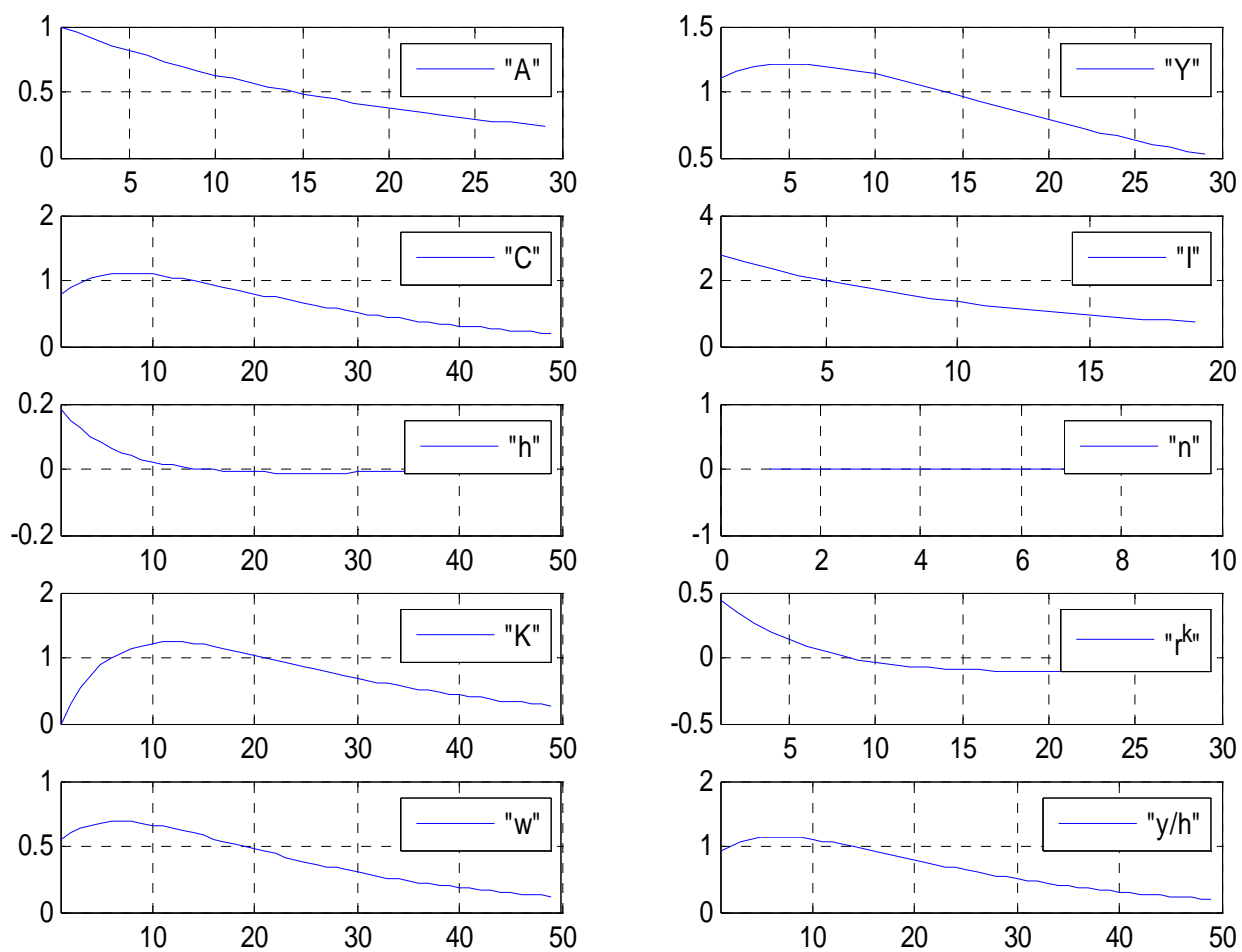
Figure 2b: Impulse responses to shocks to $\theta_{t}$
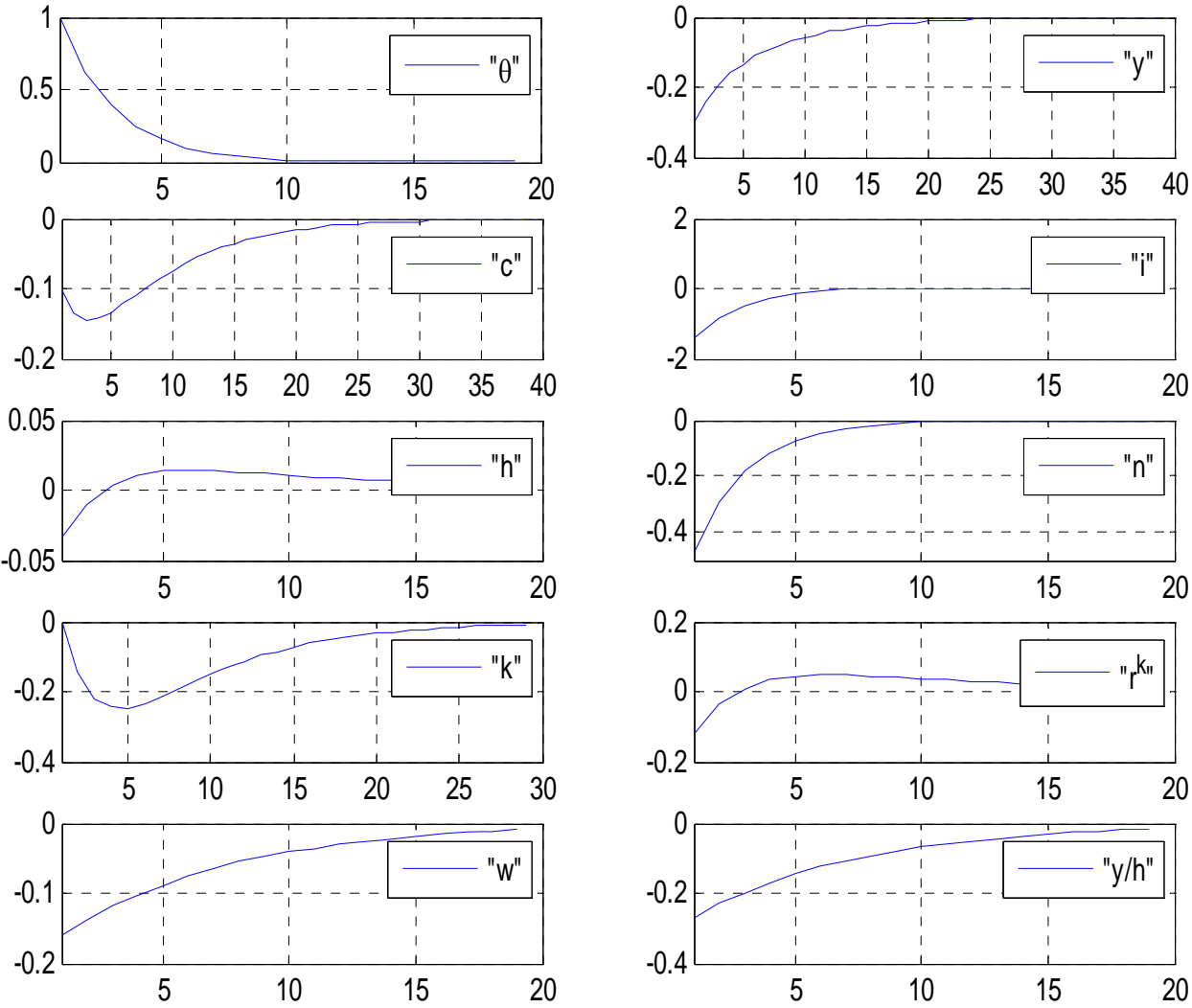
Figure 3: Hours $\left(h_{t}\right)$ and TFP (Solow Residual) for Mexico, 1980-2005

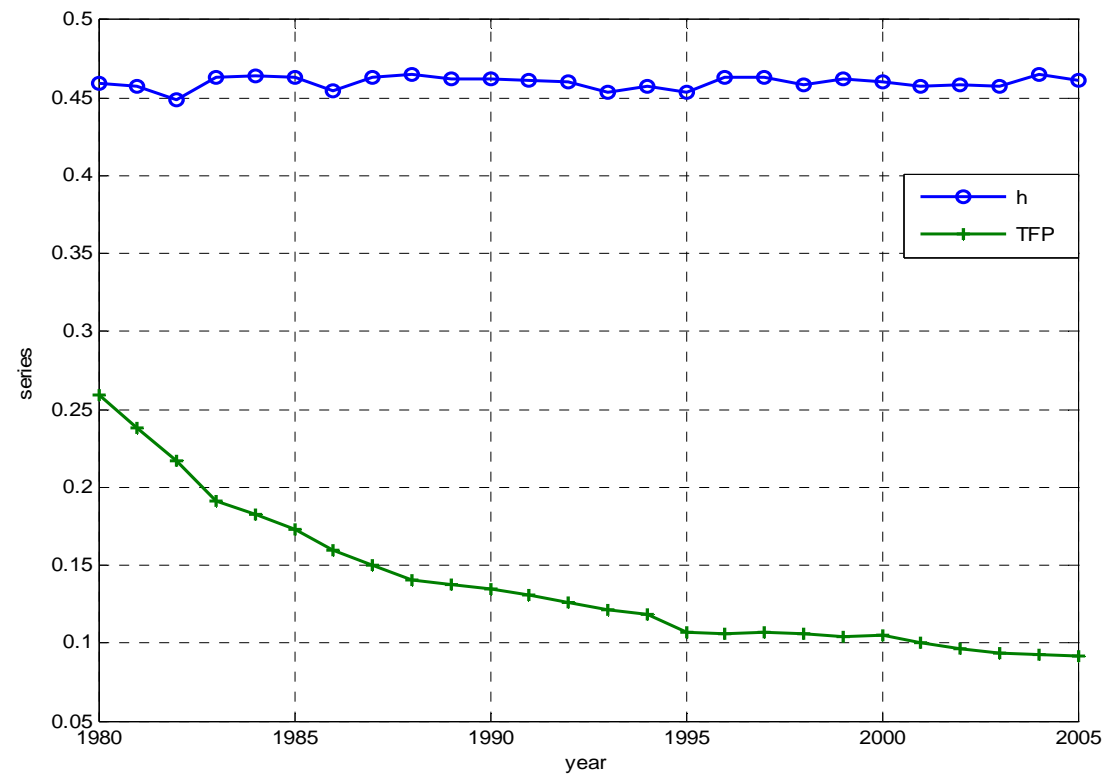


Figure 4a: ACFs and CCFs for the model with full protection of property rights (basic RBC)
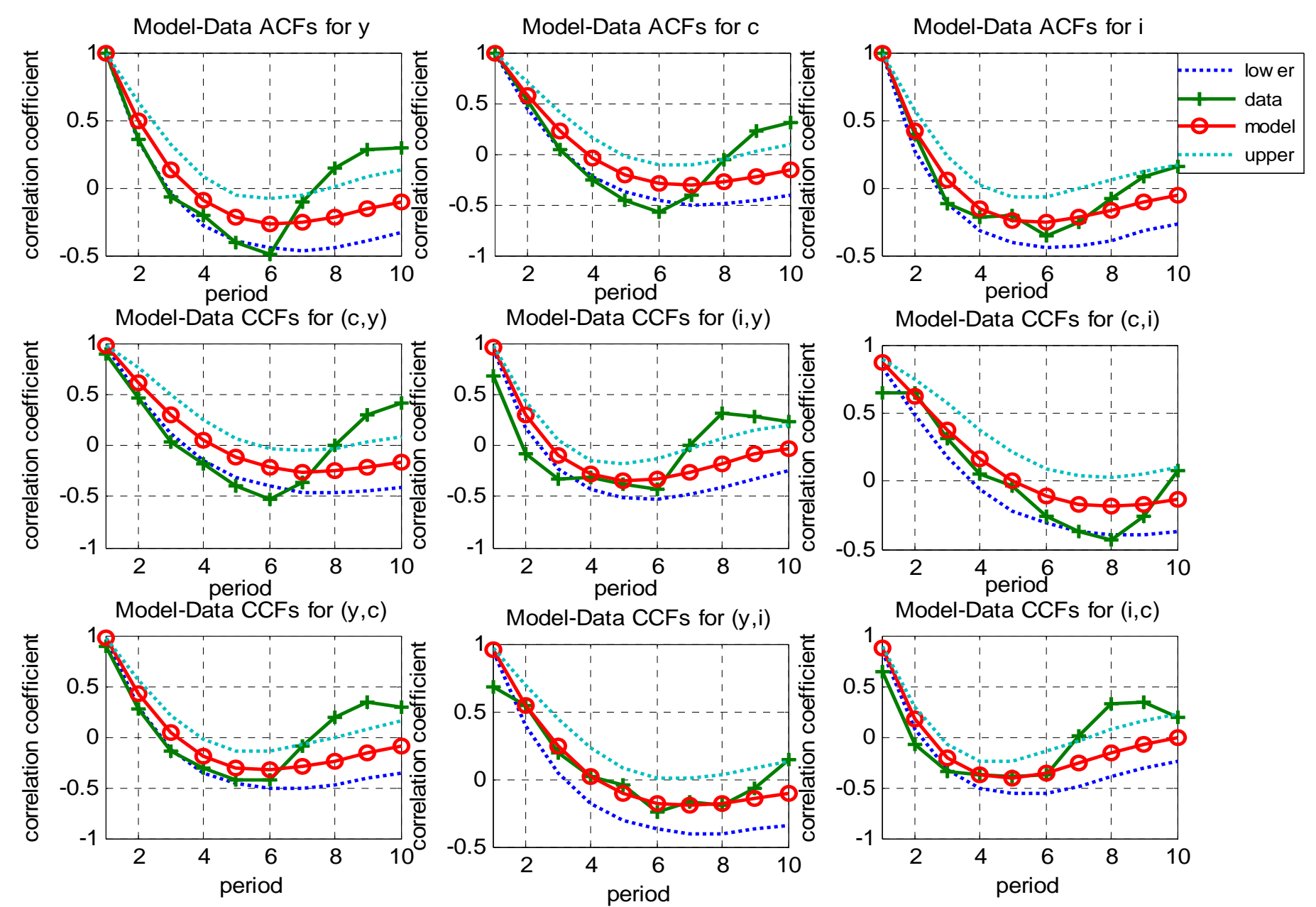
Figure 4b: ACFs and CCFs for the model with full protection of property rights (basic RBC) (continued)
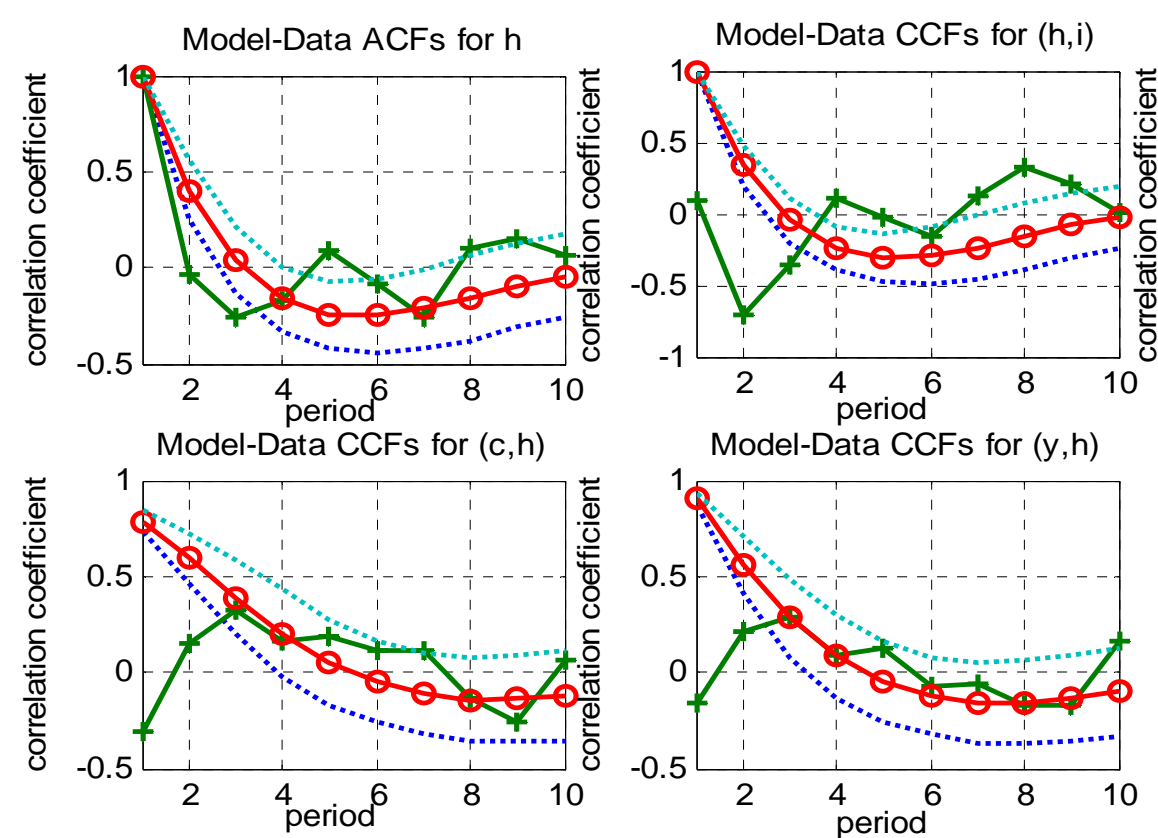

Model-Data CCFs for $(y, h)$
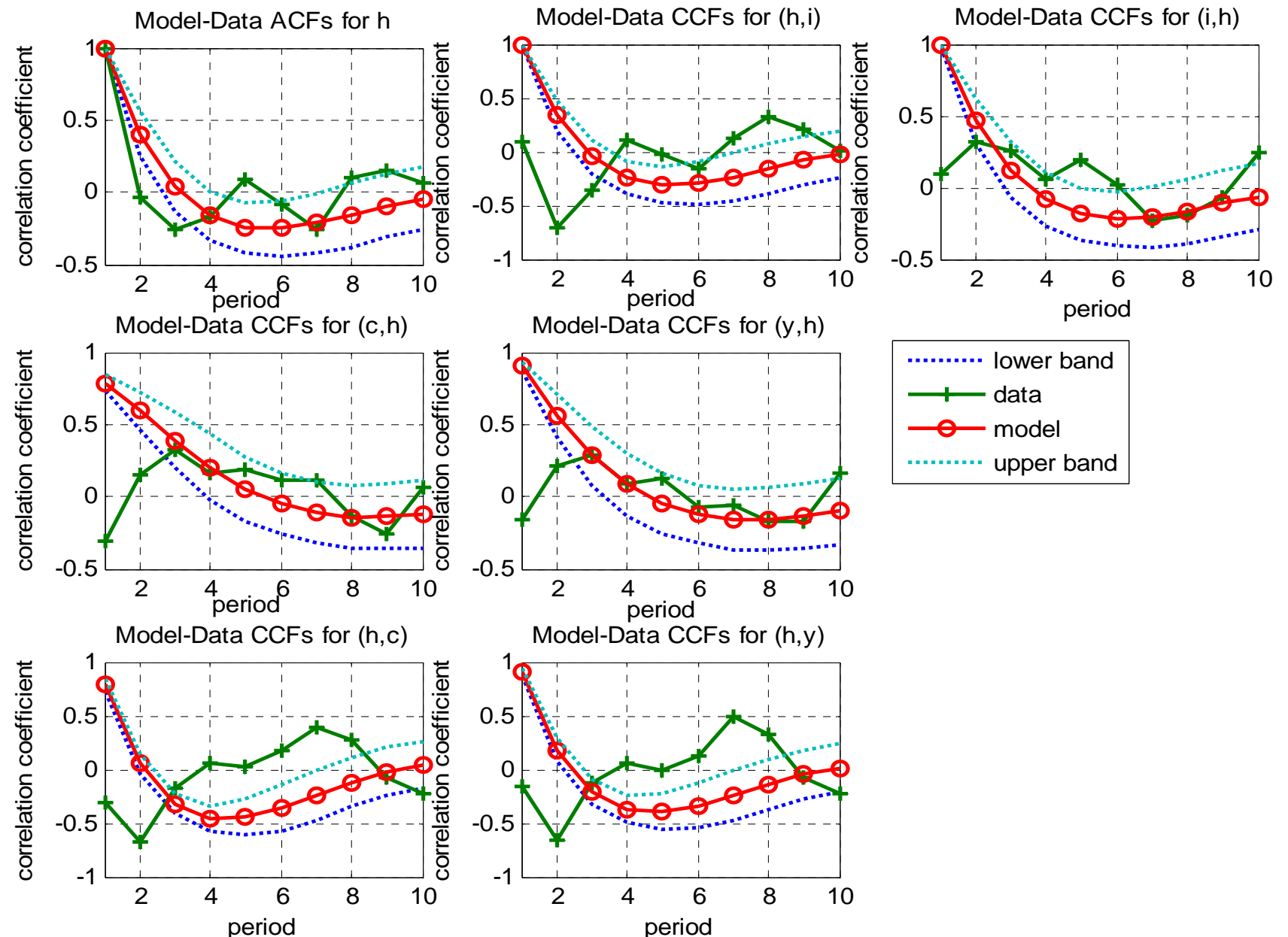

Model-Data CCFs for $(h, y)$

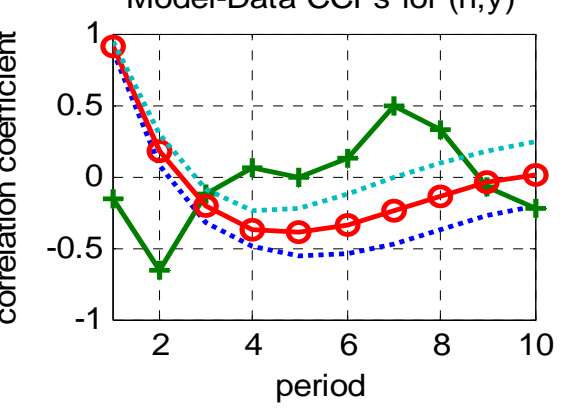


Figure 5a: Model Evaluation: ACFs and CCFs for the model with weak property rights
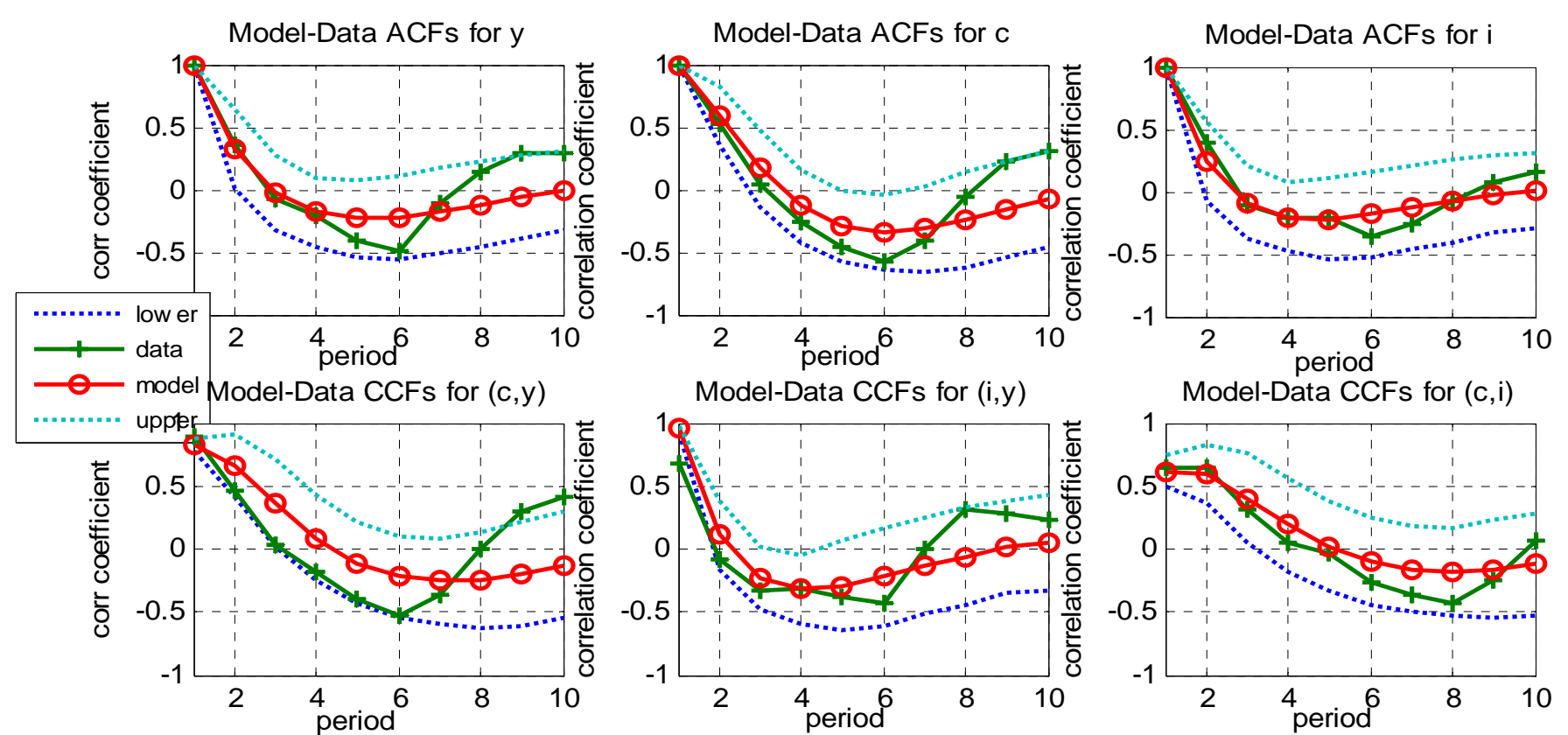

Model-Data CCFs for (c,i)
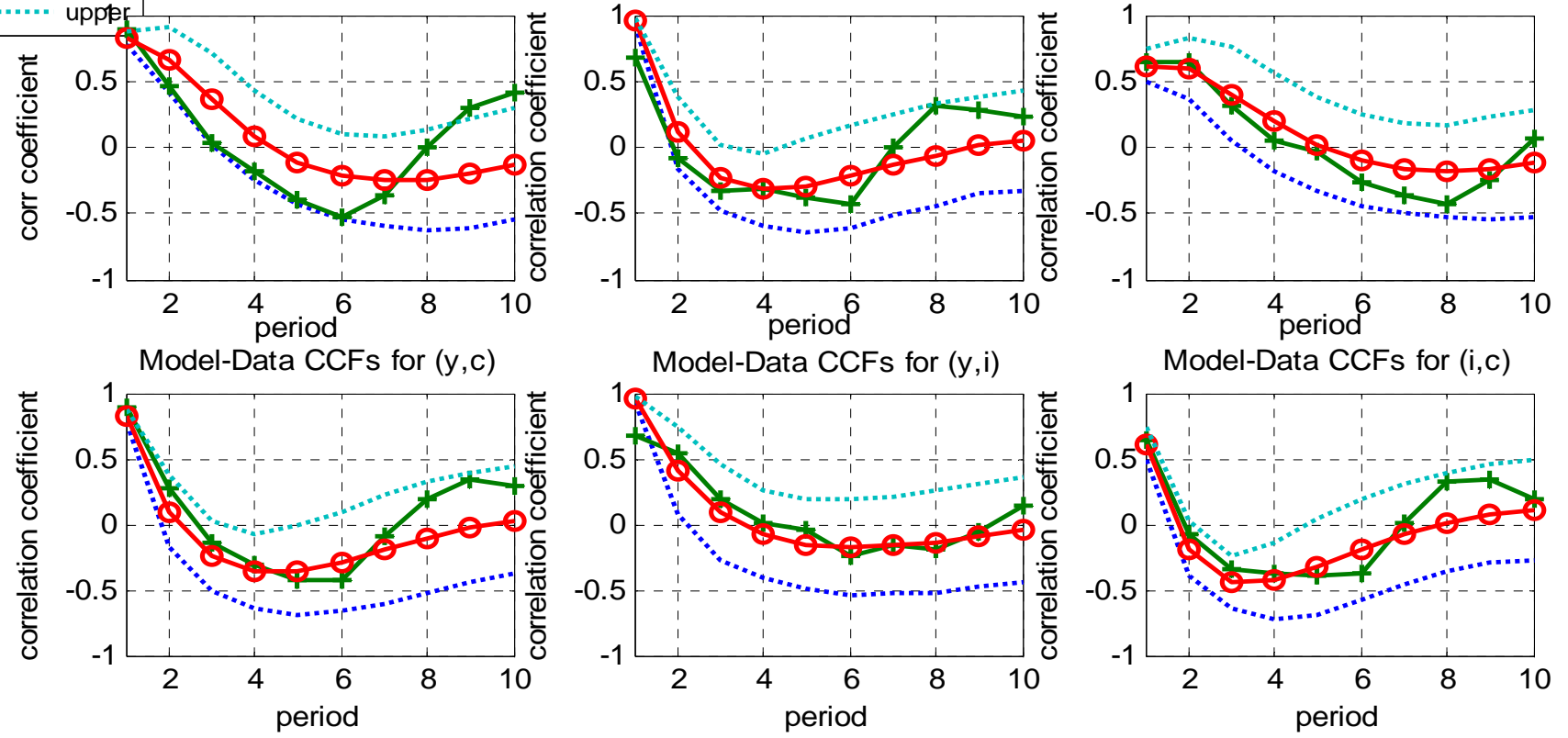

Model-Data CCFs for $(\mathrm{i}, \mathrm{c})$

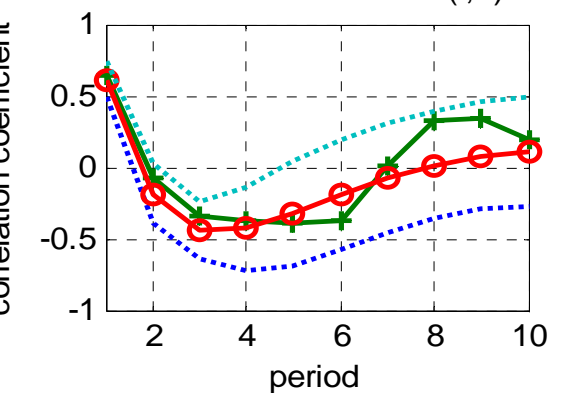


Figure 5b: Model Evaluation: ACFs and CCFs for the model with weak property rights (continued)
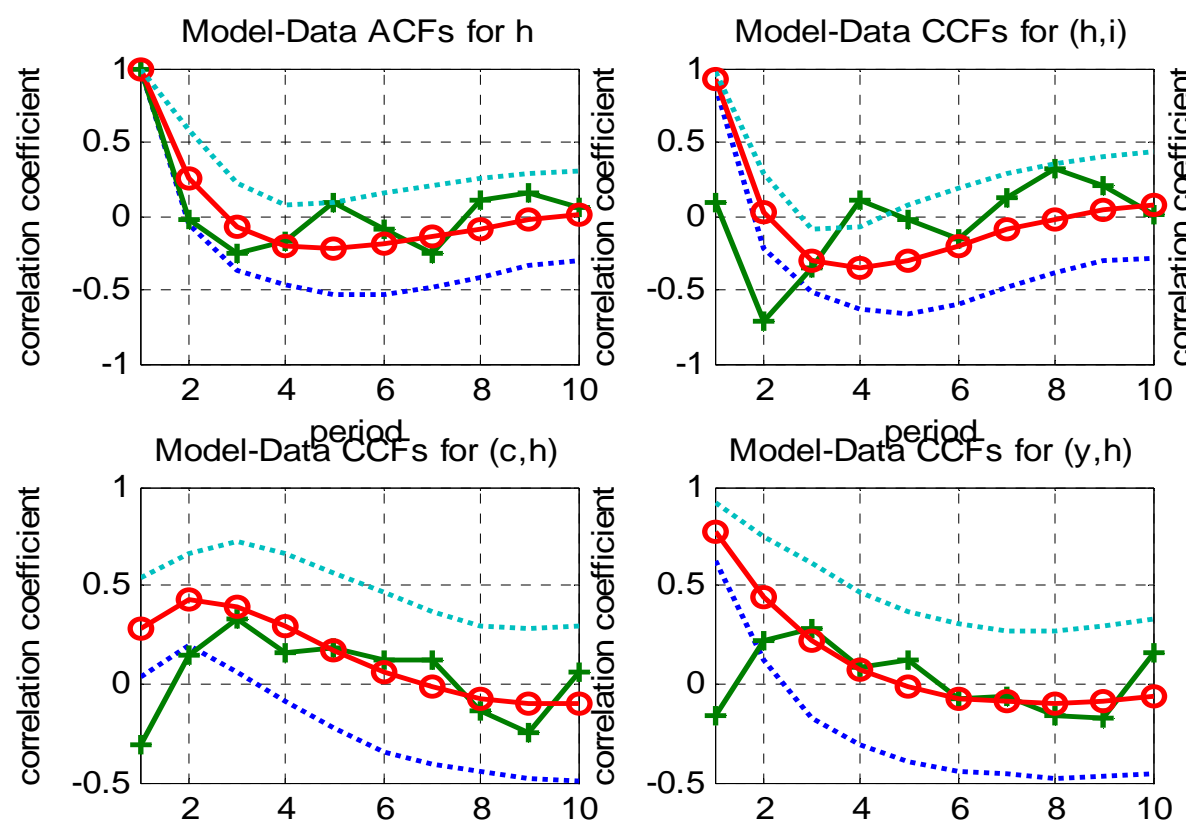

Model-Data Deriods for $(y, h)$
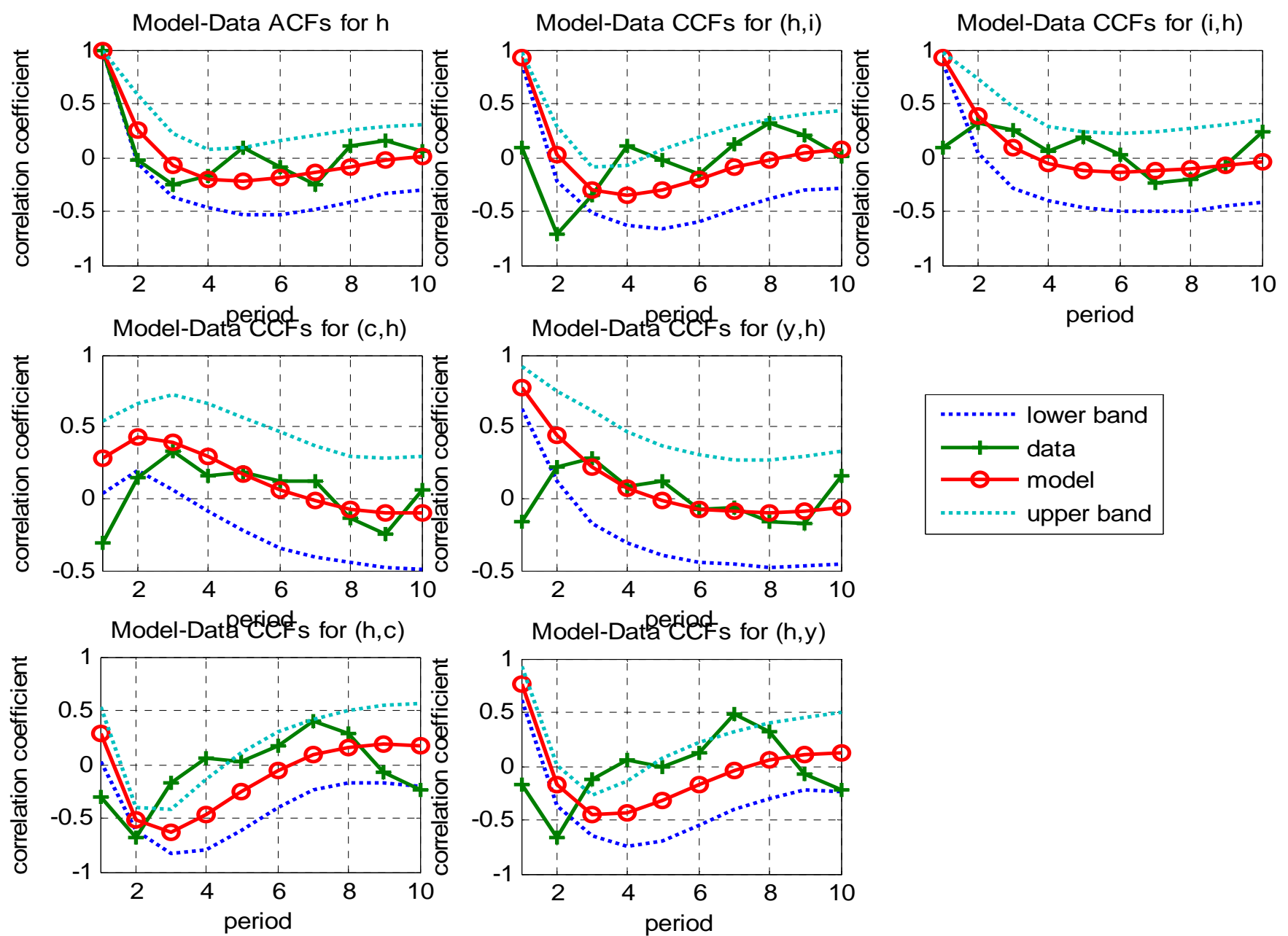
Figure 6: Log-deviations from trend for $T F P_{A t}$ and for $T F P_{\theta t}$ for Mexico, 1984-2005

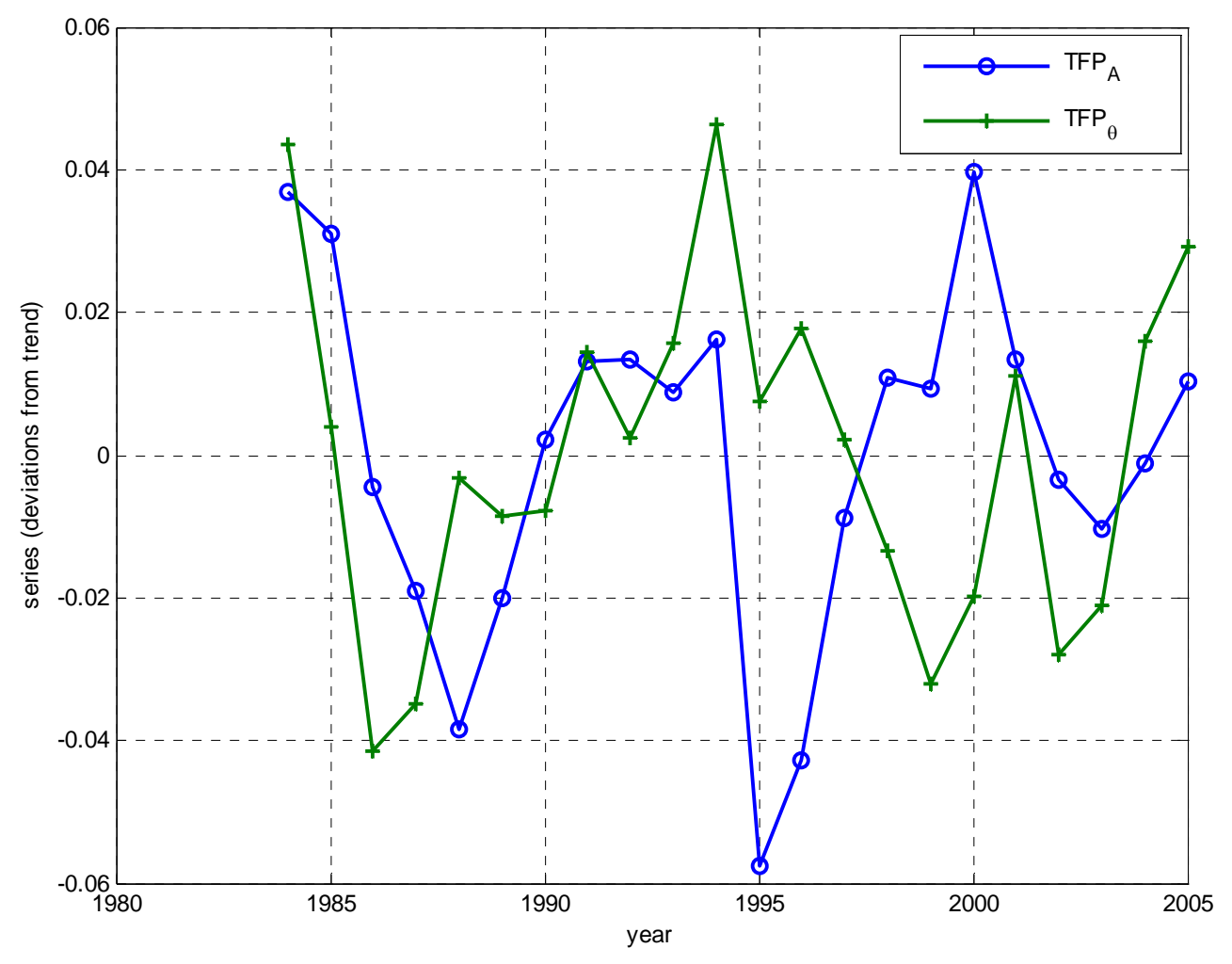


Figure 7a: Log-deviations from trend for actual and predicted $y$ for Mexico, for the models with weak and full protection of property rights

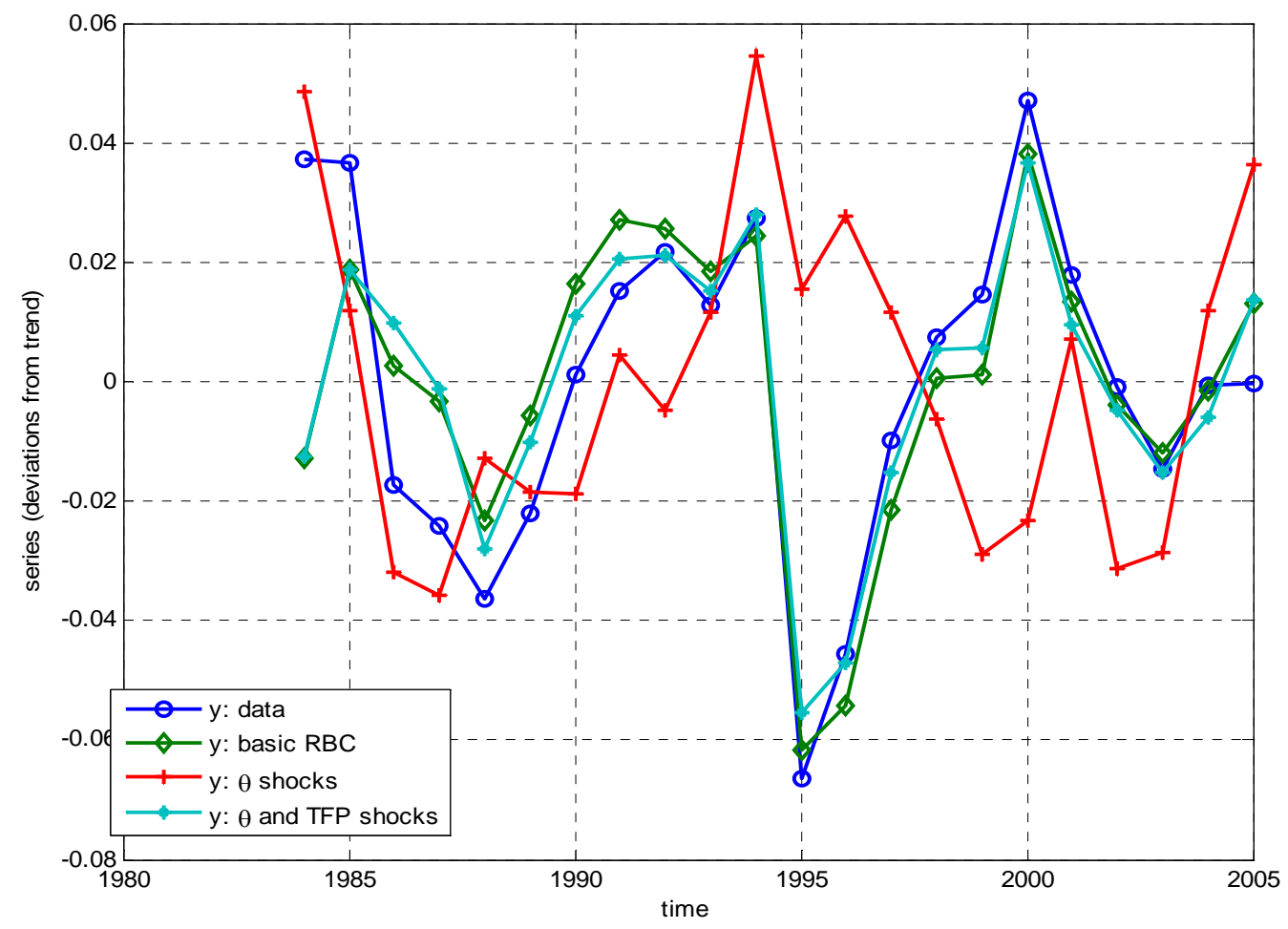

Figure 7b: Log-deviations from trend for actual and predicted $c$ for Mexico, for the models with weak and full protection of property rights

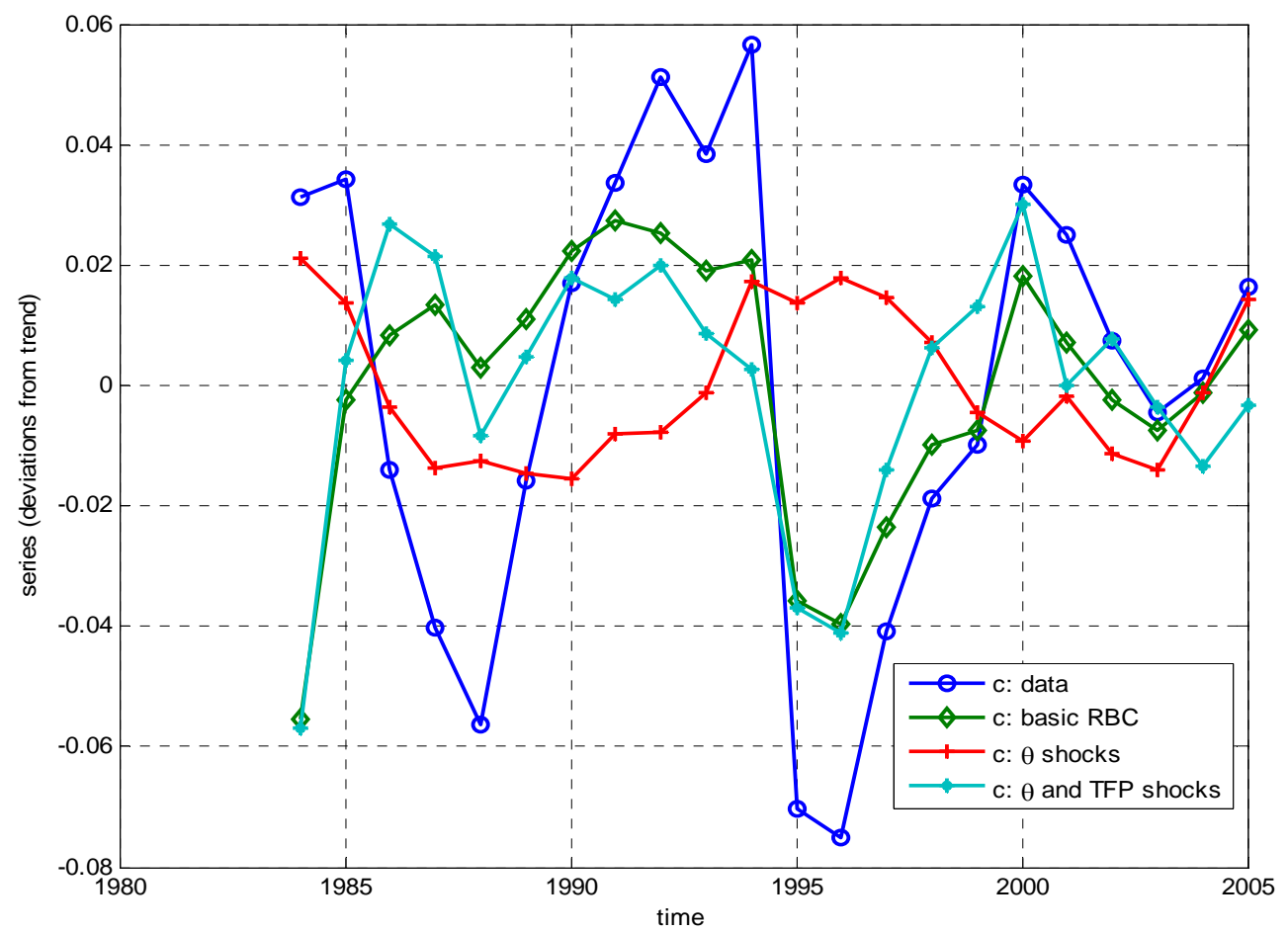


Figure 7c: Log-deviations from trend for actual and predicted $i$ for Mexico, for the models with weak and full protection of property rights

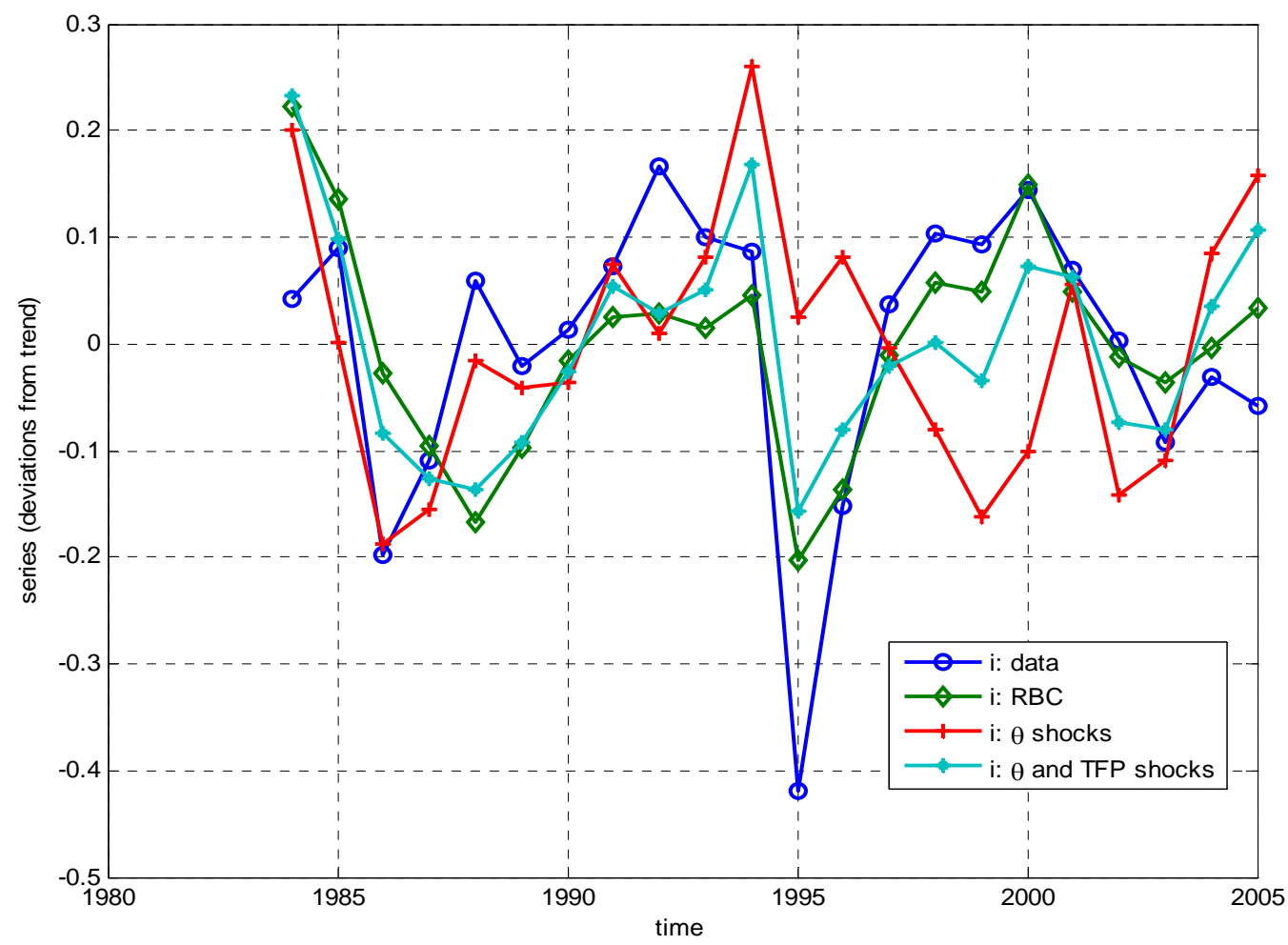

Figure 7d: Log-deviations from trend for actual and predicted $h$ for Mexico, for the models with weak and full protection of property rights

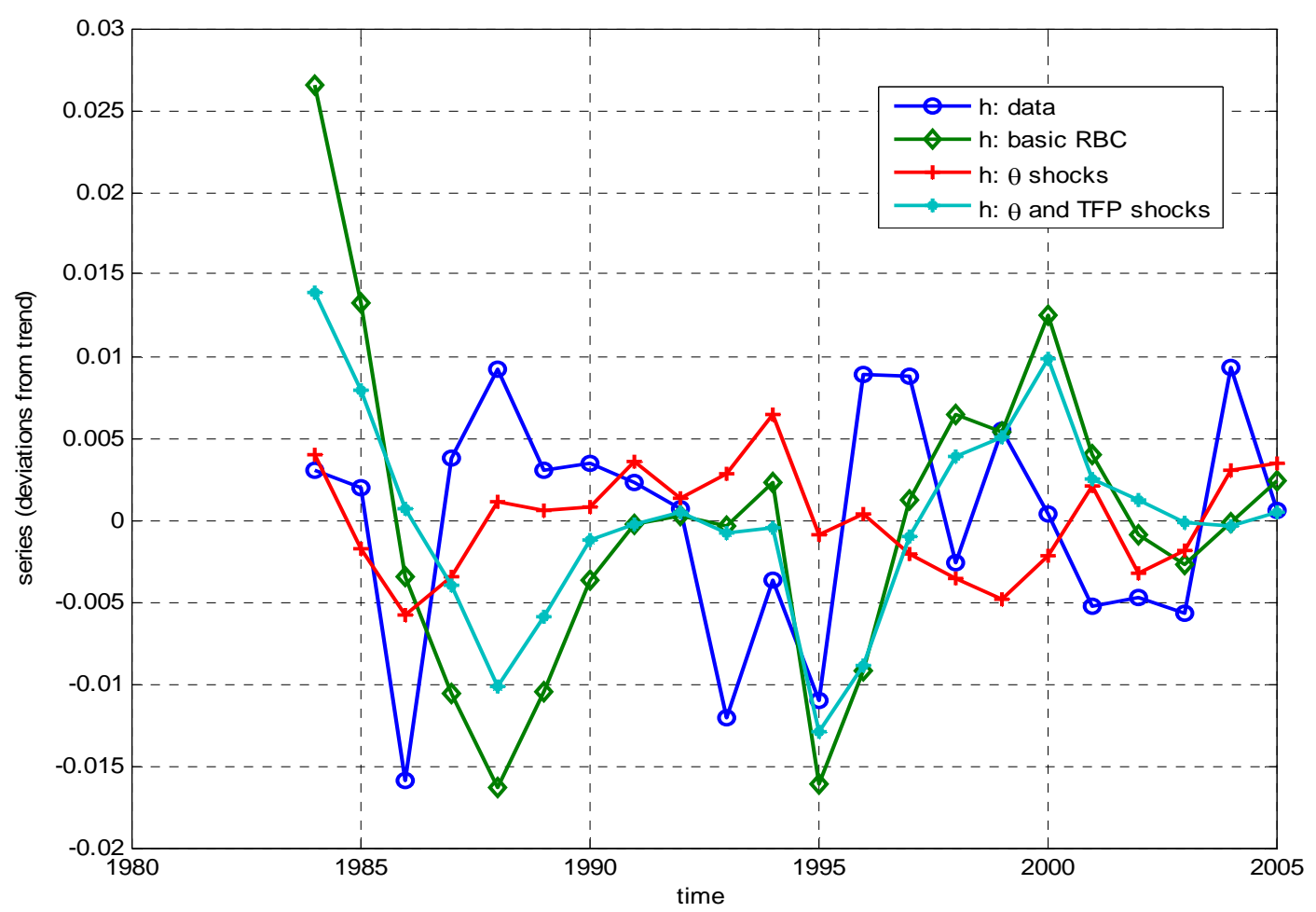




\section{References}

Acemoglu, D., S. Johnson and J. A. Robinson (2001): The colonial origins of comparative development: An empirical investigation, American Economic Review, 91, 1369-1401.

Acemoglu, D., S. Johnson and J. A. Robinson (2002): Reversal of fortune: Geography and institutions in the making of the modern world income distribution, Quarterly Journal of Economics, 118, 1231-1294.

Acemoglu, D., S. Johnson, J. A. Robinson and Y. Thaicharoen (2003): Institutional causes, macroeconomic symptoms: volatility, crises and growth, Journal of Monetary Economics, 50, 49-123.

Aguiar M. and G. Gopinath (2007): Emerging market business cycles: the cycle is the trend, Journal of Political Economy, 115, 43-68.

Baumol W. (1990): Entrepreneurship: Productive, unproductive, and destructive, Journal of Political Economy, 98, 893-921.

Bergoeing R., P. J. Kehoe, T. J. Kehoe and R. Soto (2002a): Policy-driven productivity in Chile and Mexico in the 1980's and 1990's, American Economic Review, 92, 16-21.

Bergoeing R., P. J. Kehoe, T. J. Kehoe and R. Soto (2002b): A decade lost and found: Mexico and Chile in the 1980s, Review of Economic Dynamics, 5, 166-205.

Burnside C. and M. Eichenbaum (1996):Factor-hoarding and the propagation of business-cycle shocks, American Economic Review, 86, 1154-1174.

Burnside C., M. Eichenbaum and S. Rebelo (1993): Labor hoarding and the business cycle, Journal of Political Economy, 101, 245-73.

Canova F. (2007): Methods for applied macroeconomic research. Princeton University Press, Princeton, N.J.

Chari V. V., P. J. Kehoe and E. R. McGrattan (2005): Sudden stops and output drops, American Economic Review, 2005, 95, 381-387.

Cooley T. F. and G. D. Hansen (1995): Money and the business cycle, in Frontiers of Business Cycle Research, edited by T. F. Cooley. Princeton University Press, Princeton N.J.

Drazen A. (2000): Political Economy in Macroeconomics. Princeton University Press, Princeton NJ.

Economides G., H. Park and A. Philippopoulos (2007): Optimal protection of property rights in a general equilibrium model of growth, Scandinavian Journal of Economics, 109, 153-175.

Garcia-Verdu R. (2005): Factor shares from household survey data, Banco de Mexico Working Paper. 
Hall R. and C. Jones (1999): Why do some countries produce so much more output per worker than others?, Quarterly Journal of Economics, 114, 83-116.

Ho M. and D. Jorgenson (2000): Educational policies to stimulate growth, in Using Dynamic General Equilibrium Models for Policy Analysis, edited by G. W. Harrison, S. E. H. Jensen, L. H. Pedersen, and T. H. Rutherford. North-Holland, Amsterdam.

Kehoe T. J. and K.J. Ruhl (2007): Sudden stops, sectoral reallocation and the real exchange rate, University of Texas at Austin mimeo.

King R. G. and S. T. Rebelo (1999): Resuscitating real business cycles, in The Handbook of Macroeconomics, edited by J. Taylor and M. Woodford. North-Holland, Amsterdam.

Klein P. (2000): Using the generalized Schur form to solve a multivariate linear rational expectations model, Journal of Economic Dynamics and Control, 24, 1405-1423.

Knack S. and P. Keefer (1995): Institutions and economic performance: Cross-country tests using alternative measures, Economics and Politics, 7, 207-227.

Kollintzas T. and V. Vassilatos (2000): A small open economy model with transaction costs in foreign capital, European Economic Review, 44, 1515-1541.

Kydland F. E. (1995): Business cycles and aggregate labor market fluctuations, in Frontiers of Business Cycle Research, edited by T. F. Cooley. Princeton University Press, Princeton N.J.

Lustig, N. (2001): Life is not easy: Mexico's quest for stability and growth, The Journal of Economic Perspectives, 15, 85-106.

Mauro P. (1995): Corruption and growth, Quarterly Journal of Economics, 110, 681-712.

Meza F. and E. Quintin (2007): Financial crises and total factor productivity, Federal Reserve Bank of Dallas Working Paper.

Mueller D. (2003): Public Choice III. Cambridge University Press, Cambridge.

Murphy K., A. Shleifer and R. Vishny (1991): The allocation of talent: Implications for growth, Quarterly Journal of Economics, 106, 503-530.

Neumeyer P. A. and F. Perri (2005): Business cycles in emerging economies: the role of interest rates, Journal of Monetary Economics, 52, 345-380.

North D. C. (1990): Institutions, Institutional Change and Economic Performance. Cambridge University Press, Cambridge.

Parente S. L. and E. C. Prescott (2000): Barriers to Riches. MIT Press, Cambridge Mass.

Prescott E. C. (1998): Needed: A theory of total factor productivity, International Economic Review, 39, 525-551. 
Rebelo S. (2005): Real business cycle models: past, present and future, Scandinavian Journal of Economics, 107, 217-238.

Rodrik D. (1999): Where did all the growth go? Journal of Economic Growth, 4, 385-412. 